\title{
WestVirginiaUniversity
}

THE RESEARCH REPOSITORY @ WVU

Graduate Theses, Dissertations, and Problem Reports

2018

\section{Combustion Analysis Of An Off-Road Spark Ignition Gaseous Fuel Engine}

Allan Yao

Follow this and additional works at: https://researchrepository.wvu.edu/etd

\section{Recommended Citation}

Yao, Allan, "Combustion Analysis Of An Off-Road Spark Ignition Gaseous Fuel Engine" (2018). Graduate Theses, Dissertations, and Problem Reports. 7282.

https://researchrepository.wvu.edu/etd/7282

This Thesis is protected by copyright and/or related rights. It has been brought to you by the The Research Repository @ WVU with permission from the rights-holder(s). You are free to use this Thesis in any way that is permitted by the copyright and related rights legislation that applies to your use. For other uses you must obtain permission from the rights-holder(s) directly, unless additional rights are indicated by a Creative Commons license in the record and/ or on the work itself. This Thesis has been accepted for inclusion in WVU Graduate Theses, Dissertations, and Problem Reports collection by an authorized administrator of The Research Repository @ WVU. For more information, please contact researchrepository@mail.wvu.edu. 


\title{
COMBUSTION ANALYSIS OF AN OFF-ROAD SPARK IGNITION GASEOUS FUEL ENGINE
}

\author{
Allan Yao \\ Thesis submitted to the Benjamin M. Statler College of Engineering and Mineral \\ Resources \\ at West Virginia University \\ in partial fulfillment of the requirements \\ for the degree of \\ Master of Science \\ in \\ Mechanical Engineering \\ Hailin Li, Ph. D., Committee Chairperson \\ Vyacheslav Akkerman, Ph. D. \\ Cosmin Dumitrescu, Ph. D. \\ Department of Mechanical and Aerospace Engineering \\ Morgantown, West Virginia \\ 2018
}

Keywords: Spark Ignition Engine, Natural Gas, Heat Transfer, Woschni Equation

Copyright 2018 Allan Yao 


\title{
Abstract \\ COMBUSTION ANALYSIS OF AN OFF-ROAD SPARK IGNITION GASEOUS FUEL ENGINE
}

\begin{abstract}
Allan Yao
The accurate calculation of the heat loss from bulk gas to engine coolant is critical for the optimization of the engine cooling system, calculation of the heat release rate, and improvement of the engine efficiency. The heat transfer coefficient of the traditional diesel and gasoline engines has been well documented. However, the research specific for the heat loss of spark ignition (SI) engine operating on gaseous fuels is limited.

This research developed a revised Woschni equation scaling factor for a Weichai turbocharged SI WP-10 engine operated on gaseous fuels. The engine was a 6 cylinder, 9.7 Liter stoichiometric engine developed to operate on gaseous fuels. The specific heat ratio was derived by calculating the specific heat of bulk gas which was a function of bulk gas mixture composition, and temperature. The scaling factors of the heat transfer coefficient was developed based on the hypothesis that the heat release rate was zero prior to the beginning and after the completion of combustion. When operated at full load, the scaling factors of the heat transfer coefficient for this engine was $0.34,0.33$, and 0.32 when operated on natural gas, natural gas \& carbon dioxide, and natural gas \& propane, respectively. Utilizing the revised Woschni equation, the heat release rate was calculated for each fuel. The effect of fuel composition and spark timing on cylinder pressure, heat release rate, mass fraction burned, combustion duration, and heat loss was analyzed. As expected, the blending of carbon dioxide to natural gas elongated the ignition delay, retarded the combustion phasing, and elongated the combustion duration. In comparison, the blending of propane accelerated the combustion process as indicated by the shorter combustion duration and ignition delay, and also the increased peak cylinder pressure. The effect of the fuel composition on the exhaust emissions before and after the three-way catalyst was also examined and presented.
\end{abstract}




\section{ACKNOWLEDGMENTS}

To my great mentor and helpful research advisor that I owed my wonderful research opportunity, Dr. Hailin Li. He was willing to take a chance on allowing me to work under him even when I decided to switch majors. He was patient and would always provide help after the countless mistakes I made throughout my work, research and thesis. He was always available for help when I needed it and never turned me down. I will always be truly grateful!

I am grateful for the research data collected by Weichai America Corporation. I am especially thankful for the expertise and technical support from Mr. Xin Shi, and Dr. Fuming Xiao in assisting the experimental methodology.

To my many professors that provided a positive learning environment and interesting classes. To the members of the CAFEE lab, especially Brad Ralston who mentored me when I was working there. I would also like to thank Dr. Vyacheslav Akkerman and Dr. Cosmin Dumitrescu for teaching my favorite classes and joining my thesis committee to give me crucial feedback to finalize my thesis.

I am sincerely grateful to everyone in West Virginia University Graduate Office, especially Constinia Charbonnette and Katherine Karraker for providing the funding with the STEM Mountains of Excellence of Fellowship for assisting with the research project.

I am grateful to my family, who provided me with emotional and moral support throughout my graduate student life.

Finally, I would like to thank everyone that I met in the awesome graduate program during my time at West Virginia University.

Thank you everyone! 


\section{Table of Contents}

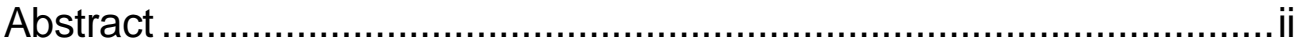

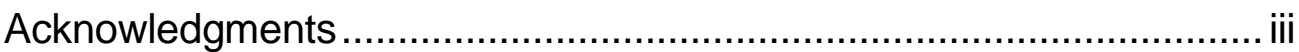

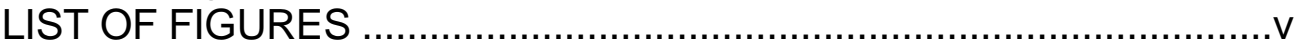

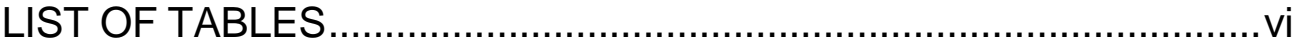

LIST OF SYMBOLS ……............................................................ vii

LIST OF ABBREVIATIONS ........................................................

Chapter 1 Introduction................................................................. 1

Chapter 2 Literature Review ............................................................. 4

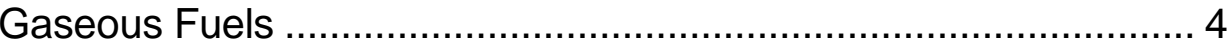

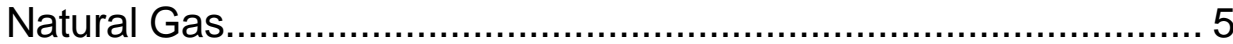

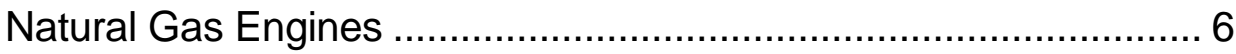

Internal Combustion Engine Technology .................................... 10

Aftertreatment \& Three Way Catalyst ........................................ 11

Heat Transfer Coefficient............................................................ 13

Chapter 3 Experimental Setup................................................... 16

Chapter 4 Combustion Analysis and Heat Transfer Model ................. 19

Base Heat Release Model...................................................... 19

Estimation of Bulk Gas Temperature at Intake Valve Closing ....... 20

Calculation of Bulk Mixture Temperature and Pressure ................ 21

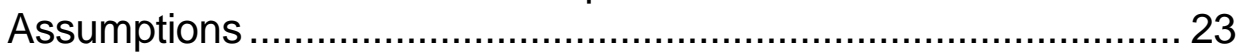

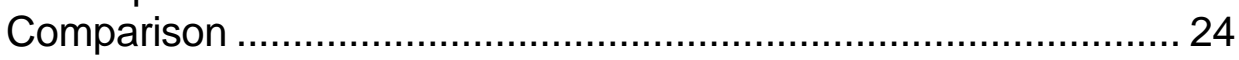

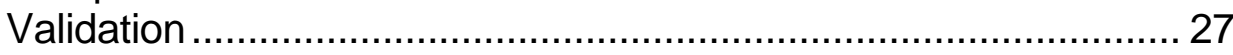

Chapter 5 Combustion Process of SI Turbo Natural Gas Engine ....... 31

Chapter 6 Small Engine Instrumentation ......................................... 41

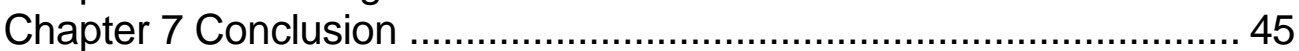

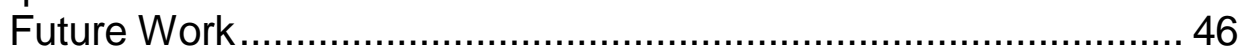

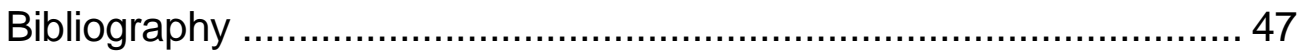

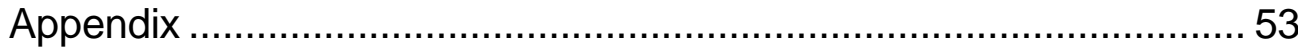




\section{LIST OF FIGURES}

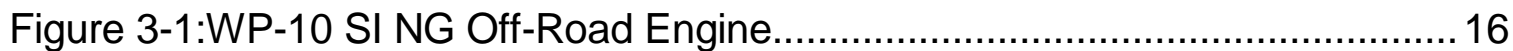

Figure 4-1: Cylinder Pressure Data, Fuel: NG. ST: $22.5^{\circ}$ CA BTDC ...................2. 24 Figure 4-2: Industry Method for Specific Heat Ratio Calculations Fuel: NG ST: $22.5^{\circ}$

CA BTDC 25

Figure 4-3: Specific Heat Ratio Variation, Fuel: NG, ST: 22.5 CA BTDC.............25

Figure 4-4: Industry Calculated Gross Heat Release Rate Vs. Woschni Calculated Gross Heat Release Rate, Fuel: NG. ST: $22.5^{\circ}$ CA BTDC ......................26

Figure 4-5: Mass Fraction Burned Comparison. Fuel: NG. St: $20.5^{\circ}$ CA BTDC ....27

Figure 4-6: Measured and Calculated Pressure Utilizing Woschni Heat Release Equation, Release Rate, Fuel: NG. ST: $22.5^{\circ} \mathrm{CA}$ BTDC ..........................28

Figure 5-1: The effect of spark timing on cylinder pressure. Fuel: NG ..................31

Figure 5-2: The effect of spark timing on gross heat release. Fuel: NG ............... 32

Figure 5-3: The effect of spark timing on mass fraction burned. Fuel: NG ........... 32

Figure 5-4:The effect of fuel composition on cylinder pressure. $\mathrm{NG}, \mathrm{NG}+\mathrm{CO}_{2}$ and $\mathrm{NG}+$ Propane, ST: $20.5^{\circ} \mathrm{CA}$ BTDC.

Figure 5-5: The effect of fuel composition on gross heat release rate, ST: $20.5^{\circ} \mathrm{CA}$ BTDC

Figure 5-6: The effect of fuel composition in heat loss. ST: $20.5^{\circ} \mathrm{CA}$ BTDC......... 36

Figure 5-7: The effect of fuel composition in mass fraction burned. ST: $-22.5^{\circ} \mathrm{CA}$ BTDC 37

Figure 6-1: 3500W Champion Electric Generator .............................................. 41

Figure 6-2: Pressure Transducer and Sleeve Modification ................................ 42

Figure 6-3: Pressure Transducer Sleeve Placement ......................................... 43

Figure 6-4: BEI H25 Incremental Encoder Mount Assembly ............................... 43

Figure 6-5: Century Link Tri-fuel Conversion Kit ................................................ 44 


\section{LIST OF TABLES}

Table 2-1: Typical Chemical Composition of Natural Gas in the United States.......6

Table 3-1: Engine Parameters.................................................................. 17

Table 3-2: Heating Value of Fuels ................................................................ 18

Table 4-1: Percent Error between Calculated and Measured Pressure ................ 28

Table 4-2: Heat Release Rate Validation .....................................................29

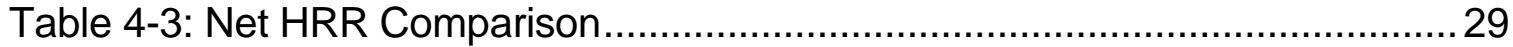

Table 4-4: Calculated Woschni Coefficients for Fuels.........................................30

Table 5-1: Spark Timing Impact on Combustion Phasing, Fuel: NG .................... 33

Table 5-2: Total Heat Loss ........................................................................ 35

Table 5-3: Fuel Impact On Combustion Phasing. ST: $20.5^{\circ} \mathrm{CA}$ BTDC ................. 36

Table 5-4: Fuel Composition Impact on Ignition Delay \& Combustion Duration for

Different Fuel Mixtures. ST: $20.5^{\circ} \mathrm{CA}$ BTDC ........................................ 37

Table 5-5: Engine Out Emissions. ST: $20.5^{\circ} \mathrm{CA}$ BTDC. Unit: g/bhp-hr................ 38

Table 5-6: After-Treatment Out Exhaust Emissions. (g/bhp-hr) ST: $20.5^{\circ} \mathrm{CA}$ BTDC

Table 5-7: Exhaust Emissions and Regulations of EPA and CARB, g/bhp-hr....... 39

Table A-1: Constant Values for Methane Shomate Equations..............................53

Table A-2:Constant Value for Oxygen Shomate Equations .................................53

Table A-3: Constant Value for Nitrogen Shomate Equations ...............................53

Table A-4: Constant Value for Carbon Dioxide Shomate Equations .....................54

Table A-5: Constant Value for Water(Gas) Shomate Equations ........................... 54 


\section{LIST OF SYMBOLS}

A Heat transfer surface area

$A_{p}$ Piston area

$c_{p}$ Specific heat capacity under constant pressure

$c_{\mathrm{v}}$ Specific heat capacity under constant volume

D Cylinder bore

h Heat transfer coefficient

$\mathrm{H}_{\mathrm{p}}$ Enthalpy of products

$\mathrm{H}_{\mathrm{r}}$ Enthalpy of reactants

$\mathrm{m}_{\text {air }}$ Air mass per cycle

$\mathrm{m}_{\mathrm{CO}_{2}} \mathrm{CO}_{2}$ mass per cycle

$m_{\text {final species }}$ Final mass of species

$\mathrm{m}_{\text {fuel2 }}$ Intake mass of fuel per cycle

$\mathrm{m}_{\text {fuel3 }}$ Intake mass of fuel \#2 per cycle

$\mathrm{m}_{\text {intake }}$ Intake mass per cycle

$\mathrm{m}_{\text {intake addition }}$ Added intake mass per cycle excluding fuel

$m_{\text {initial species }}$ Initial mass of species

$\mathrm{m}_{\text {fuel1 }}$ Intake mass of fuel per hour

$\mathrm{m}_{\text {fresh }}$ Fresh mass per cycle

$\mathrm{m}_{\text {residual }}$ Residual mass per cycle

$\mathrm{m}_{\text {species,initial }}$ Initial species mass 
$M_{\text {species }}$ Molecular weight of species

$\mathrm{n}_{\text {cylinders }}$ \# of cylinders

$\mathrm{p}$ Instantaneous pressure in cylinder $(\mathrm{kPa})$

$\mathrm{p}_{0}$ Motoring pressure (only compression) $(\mathrm{kPa})$

$\mathrm{p}_{\mathrm{r}}$ Reference state of pressure $(\mathrm{kPa})$

$\mathrm{P}_{\mathrm{BDC}}$ Pressure at BDC

$\mathrm{P}_{\text {calc }}$ Calculated pressure

Q Heat transfer $(\mathrm{kJ})$

$\mathrm{R}_{\text {mixture }}$ Gas constant of the mixture

$\mathrm{R}_{\mathrm{u}}$ Universal gas constant

$\mathrm{T}_{\text {exhaust }}$ Exhaust temperature

$\mathrm{T}_{\mathrm{g}}$ Instantaneous temperature in the cylinder (Kelvin)

$\mathrm{T}_{\text {initial }}$ Initial temperature in the cylinder

$\mathrm{T}_{\mathrm{n}}$ Temperature at next crank angle

$\mathrm{T}_{\mathrm{n}-1}$ Temperature at previous crank angle

$\mathrm{T}_{\mathrm{r}}$ Reference state temperature (Kelvin)

$\mathrm{T}_{\mathrm{W}}$ Chamber surface temperature (Kelvin)

U Average gas velocity $\left(\frac{\mathrm{m}}{\mathrm{s}}\right)$

V Cylinder volume $\left(\mathrm{m}^{3}\right)$

$\mathrm{v}_{\text {engine }}$ Engine Speed (RPM)

$\forall_{\mathrm{d}}$ Total cylinder volume $\left(\mathrm{m}^{3}\right)$ 
$\mathrm{V}_{\min }$ Minimum cylinder volume

$\mathrm{V}_{\mathrm{o}}$ Initial cylinder volume $\left(\mathrm{m}^{3}\right)$

$\mathrm{V}_{\mathrm{p}}$ Piston cylinder speed (m/s)

$\mathrm{V}_{\mathrm{r}}$ Reference state cylinder volume $\left(\mathrm{m}^{3}\right)$

W Work produced at each crank angle

$\gamma$ Specific heat ratio

$\alpha$ Scaling factor

$\% \mathrm{MF}_{\text {fresh }}$ Percentage of mass fraction of fresh mixture

$\% \mathrm{MF}_{\text {residual }}$ Percentage of mass fraction of residual mixture

$\% \mathrm{MF}_{\text {final }}$ Percentage of mass fraction of final mixture 


\section{LIST OF ABBREVIATIONS}

BDC Bottom dead center

BSFC: Brake specific fuel consumption

BSME: Brake specific mean emission

BTDC: Bottom dead center

BTE: Brake thermal efficiency

BTU: British Thermal Unit

CA Crank angle

CO Carbon monoxide

$\mathrm{CO}_{2}$ Carbon dioxide

CHP Combined heat and power

CNG Compressed Natural Gas

DOE Department of Energy

EGR Exhaust Gas Recirculation

EIA Energy Information Administration

EPA Environmental Protection Agency

GC Gas chromatography

GDI Gasoline direct injection

HC Hydrocarbon

HD Heavy duty

HFID Heated flame ionization detector

HHV Higher heating value 
HRR Heat release rate

ICE Internal Combustion Engine

LA Los Angeles

LD Light duty

MFB Mass fraction burned

mmBTU Million british thermal unit

NDIR Non-dispersive infrared

NGV Natural Gas Vehicles

NIST National Institute of Standards and Technology

NOx Nitrogen oxides

NMHC Non-methane hydrocarbon

OSC Oxygen storage capacity

Pd Palladium

RDE Real Driving Emissions

SI Spark Ignition

ST Spark timing

THC total hydrocarbon

TWC Three-way catalyst

US United States 


\section{Chapter 1 Introduction}

Energy consumption throughout the world has continued to increase at an unrelenting pace. As the population from every part of the world is being lifted off of property, the demand for energy will continue to increase in the future to quench the world's thirst for energy. Over the last century, the majority of energy was generated from one type of environmentally destructive type of fossil fuel: coal. However, the advancements in hydraulic fracturing, horizontal drilling, real-time logging analytics and programmable drillheads allowed the United States to tap an energy resource: shale, which was not economically feasible before the $21^{\text {st }}$ century. Furthermore, for the first time in decades, the Energy Information Administration (EIA) estimates that the United States (US) will become a net exporter of energy instead of a net importer, which is projected to happen in just 4 more years [1]. In addition, based on the current advancement of technology as of year 2018, natural gas (NG) will account for nearly $40 \%$ of United States total energy production by 2050 [1]. One of the major factors for the rapid increase in adoption of NG originates from it being one of the cleanest hydrocarbon fuels in the world. It has a low carbon footprint while the byproducts after combustion is significantly cleaner than gasoline or diesel. For instance, the major byproducts of $\mathrm{NG}$ combustion are carbon dioxide $\left(\mathrm{CO}_{2}\right)$ and water vapor. Furthermore, the emissions of nitrous oxides ( $\mathrm{NOx})$, hydrocarbon $(\mathrm{HC})$, carbon monoxide (CO) and particulate matter (PM) from NG engines are significantly lower than emissions from diesel engines. With the low prices of NG in the United States, it has now become a fuel with comparable performance relative to its economics to justify consideration for widespread adoption. For reference, the cost of NG in US is $\$ 3$ per million 
British Thermal Unit (mmBTU), meanwhile Europe's average price is $\$ 6 / \mathrm{mmBTU}$ and Japan's average price is $\$ 8 / \mathrm{mmBTU}$ [2]. Furthermore, while the price of crude oil has risen by almost $50 \%$ in the past 2 years, the price of NG has just risen $5 \%$ [3]. In essence, the United States is positioned as one of the major world energy exporters in the coming decade.

NG has already been in use for vehicles throughout the United States, ranging from forklifts to transit buses. In addition, NG blends have also been utilized in the different types of engines. For instance, NG has high emissions of unburned hydrocarbons, which will become a factor in future emissions regulations. Therefore, $\mathrm{CO}_{2}$ has been utilized in $\mathrm{NG}$ blends on NG spark ignition (SI) engines, which will increase the engine brake specific fuel consumption (BFSC) by almost $5 \%$ due to the lower heating value of the fuel blend, but yield a reduction of $80 \%$ in NOx emissions [4]. The drastic decrease in NOx emission was mainly attributed to the lower combustion temperature. The $\mathrm{CO}_{2}$ would act as diluents similar to a diesel engine's exhaust gas recirculation (EGR) system. Furthermore, other blends, such as propane has been shown to demonstrate promise in improving the brake power of the engine, while lowering emissions as shown in a research done on SI engines in Turkey [5]. Currently, a substantial amount of NG engines in production utilize a SI system. The major factor for this situation as a result of the slower flame propagation rate of NG, subsequently resulting in increasing complications for ignition. Therefore, the SI NG engines are currently the most common NG engines found in the field. Hence, combustion modelling is extensive for SI engines, which would have defined most of the base models for simulations of heat transfer and combustion parameters. However, most of the 
combustion models have been situated for engines operating on gasoline and diesel. One of the most renowned heat transfer correlation is the Woschni correlation, which is an experimental correlation that relates the different parameters of the engine resulting in an accurate heat transfer coefficient for the combustion gases inside the cylinder during operation. The significance of the correlation was to allow engineers and researchers to simulate the gross heat transfer that occurs during operation, which would be crucial for determining the engine efficiency and energy balance. For my research, the objective was to analyze the combustion processes of a SI engine operated on different gaseous fuel mixtures. In addition, the heat loss would be calculated using experimental data from the field to iterate specific constants and scaling factor for a revised Woschni model for the different fuel mixtures that was tested. The conclusions about the significance of different fuel mixtures will be assessed to determine future feasibility of global adoption. In addition, exhaust emissions will be evaluated and compared to emissions regulations to determine current and future economic feasibility of NG engines. Finally, a small engine test cell was designed and set-up for a direct comparison between NG and gasoline. 


\section{Chapter 2 Literature Review}

\section{Gaseous Fuels}

Advancements in fossil fuel extraction technology fueled the growth in NG and crude oil production in the US. Eventually, the excess supply lead to a deterioration in the worldwide prices of crude oil and NG due to a supply glut. From October 2014 to January 2016, the price of crude oil crashed over 55\% [6], while the price of NG tumbled 30\% [7]. Nonetheless, NG and crude oil worldwide production is expected to rise about $10 \%$ in 2018 [8]. In consequence, fossil fuel consumption has also been steadily rising due to population growth and lower fuel prices throughout the world. Over the last 15 years, EIA has calculated that the energy consumption across the globe has grown by over $40 \%$ [8]. Moreover, gasoline and diesel hold over $80 \%$ of the market share for fuels utilized in transportation, while NG holds just 3\% [9]. Currently, gasoline is utilized by $55 \%$ of every vehicle in the United States [9]. The characteristics of gasoline, such as high volatility, low expense and relative abundance have helped it become and remain the indisputable fuel of choice for transportation. However, there are significant $\mathrm{CO}_{2}$ emissions, which is becoming more stringently regulated in the $21^{\text {st }}$ century. Diesel is the second most utilized fuel utilized in transportation, but especially dominates in the heavy duty industry. The main factor is diesel engines on average tend to be more efficient than their gasoline counterparts. However, diesel engines tend to be larger is due to the existence of a more complex aftertreatment system designed to reduce the PM and NOx emissions. NG is another type of fuel that is utilized for transportation, which is slowly gaining market share. The reason is that due to the relative abundance of NG with the recent NG reserve discoveries, the prices have decreased substantially, leading to the economic feasibility of 
widespread adoption. Unlike diesel and gasoline, NG have much lower emissions and a simple three-way catalyst (TWC) system can be applied to NG engines to yield regulatory complaint engines for production. However, in electricity generation, NG has become the dominant fuel source with a $32 \%$ market share in the US [10]. One of the most common types of NG power plants is combined heat power. As a result, research in this field is essential to determine the efficiency and power output of future NG engines.

\section{Natural Gas}

Across the major developed countries around the world, the United States has arguably the most advanced pipeline system for fossil fuel transportation. One of the major advantages of NG is its emissions. For example, on full engine load, NG has been shown to emit $30 \%$ less $\mathrm{CO}_{2}$ comparable to gasoline for minor setbacks in performance [11]. Furthermore, another advantage of NG is in its abundance throughout the world. It is estimated that $55 \%$ of the world's current crude oil reserves are in regions of frequent political turmoil [12]. In 2016, United States produced about an average of 8.9 million barrels of oil per day, but US consumption was about 19.7 million barrels of oil per day [13]. The difference in production and consumption has been made up from imports of petroleum products, which is usually transported from the middle east. Unlike crude oil, where most of the resources presides in the volatile regions of the middle east, NG can be found in reservoirs throughout the world. Therefore, it is unlikely that a fuel shortage will occur due to supply or geopolitics, such as the 1973 oil crisis, since a monopoly over the NG supply is unfeasible. In the US, the EIA currently estimates there are proven NG reserves of over 324 trillion cubic feet in 2016, which has risen by $5 \%$ from 2015 [14]. Based on current US 
consumption rate, the NG supplies will last for over a century. Furthermore, the NG has already been proven to work in developing countries such as Brazil and Argentina, where over 1.5 million vehicles run on solely compressed natural gas (CNG) for propulsion [15]. As a result, the United States would could definitely utilize NG during the transition between fossil fuels to green energy in the coming decades.

NG is one of the most established alternative fuels currently on the market. As shown in the Table 2-1 [16], NG is mainly composed of methane $\left(\mathrm{CH}_{4}\right)$ in addition to some heavier hydrocarbons. As a result, $\mathrm{NG}$ is usually approximated based on its $\mathrm{CH}_{4}$ qualities. If computational power is adequate, model simulations might include traces of ethane and propane, but the gases that are ranging from trace amounts to less than one percent are not generally considered in the simulation models due to computational limitations.

Table 2-1: Typical Chemical Composition of Natural Gas in the United States

\begin{tabular}{|c|c|c|}
\hline Component & \% Mole Analysis & Range $(\%$ mole $)$ \\
\hline Methane & 93.9 & $87.0-97.0$ \\
\hline Ethane & 4.2 & $1.5-9.0$ \\
\hline Propane & 0.3 & $0.1-1.5$ \\
\hline iso - Butane & 0.03 & $0.01-0.3$ \\
\hline normal - Butane & 0.03 & $0.01-0.3$ \\
\hline iso - Pentane & 0.01 & trace -0.04 \\
\hline normal - Pentane & 0.01 & trace -0.04 \\
\hline Hexanes plus & 0.01 & trace -0.06 \\
\hline Nitrogen & 1.0 & $0.2-5.5$ \\
\hline Carbon Dioxide & 0.5 & $0.05-1.0$ \\
\hline Oxygen & 0.01 & trace -0.1 \\
\hline Hydrogen & trace & trace -0.02 \\
\hline
\end{tabular}

\section{Natural Gas Engines}

Currently, in most modern vehicles NG is compressed in cylinders before it is utilized in vehicles, which is referred as CNG. The most common vehicles to use NG currently are 
construction vehicles. The main reason is that construction vehicles are generally larger, which allows for larger compression NG tanks to be utilized. NGV's, such as sedans on the road have significantly lower range due to the compact NG tank has to be fitted in the trunk or floor of the vehicle. Nonetheless, NG offers a myriad of significant advantages. NG has a higher octane number than gasoline, indicating a higher resistance to auto-ignition. Autoignition, also known as engine knock is extremely harmful for engines, since this phenomenon could destroy an engine in seconds. Auto-ignition arises due to flame detonation resulting from instantaneous combustion, leading to high pressure waves which can severely damage the engine piston, gasket, and other parts due to the loss of the boundary layer surrounding those engine parts. The reason is that the most common alloys utilized for engine piston construction is aluminum, which does not have a very high melting point. The boundary protects the cylinder from the heat, so manufacturers utilize aluminum because of its light weight and low cost. In essence, utilizing NG would help mitigate this problem by increasing the safety margin. In addition, this means that the fuel/air mixture are able to reach a significantly higher temperature and higher pressure before auto-ignition resulting in a higher energy output. This suggests that the compression ratio could be increased a higher amount on NGV than on gasoline vehicles. NG has higher low heating value than gasoline on mass basis, which means that it has a higher energy density. However, since NG is in gaseous form and gasoline is in liquid form, gasoline also have a higher net energy density. Higher compression ratios with the addition of NG are favored, but they might result in higher NOx emissions. Higher compression ratio results in lower knocking resistance, so it must be balanced. Lean combustion, which is the result of a 
higher amount of air intake required for complete combustion of fuel in the mixture results in lower power output, but rich combustion, where higher fuel intake relative to the air intake results in $\mathrm{HC}$ and $\mathrm{CO}$ emissions. Research has illustrated that lean combustion of $\mathrm{NG}$ indicated slower flame propagation relative to gasoline [17]. For this reason, ignition for NG combustion is difficult to optimize for lean combustion. Another solution is EGR, which can be utilized to reduce knock occurrence. However, this reduces the amount of air circulating in the engine, resulting in lower volumetric efficiency. Furthermore, although EGR lowers NOx emissions, it leads to higher $\mathrm{HC}$ and $\mathrm{CO}$ emissions. As the EGR rate increases, the NOx emissions decrease almost linearly, while the $\mathrm{HC}$ emissions almost increases in line with EGR rate increases. As a result, there has been different NG mixtures currently being researched to lower the emissions while subsequently causing minimal effects to engine performance. From research done by a review on the effects of $\mathrm{CO}_{2}$ and $\mathrm{NG}$ mixtures, the heating value of the fuel was decreased, which resulted in lower engine power output and thermal efficiency. The root cause of this efficiency decrease was the lower presence of $\mathrm{NG}$ and air due to the increased presence of $\mathrm{CO}_{2}$ during stoichiometric combustion. From a study done on dual-fuel engines with $\mathrm{CO}_{2}$ and $\mathrm{NG}$ mixtures, there was a $15-20 \%$ decrease in the power output due to volumetric efficiency decreases and slower flame propagation speed [4]. From the research, the carbon monoxide emissions were determined to be unaffected by the addition of $\mathrm{CO}_{2}$. The NOx emissions reduction effects were similar to the EGR effects of the diesel engine combustion systems. A more complex gaseous mixture would include propane. Propane is one of the components of NG that has a higher lower heating value, lower auto-ignition temperature by almost $100{ }^{\circ} \mathrm{C}$, and a 
higher flame propagation rate. From research done by the DOE, it was determined that with the addition of propane, the same engine power output could be achieved with $5 \%$ of propane blended into the mixture in combination with a $5-10 \%$ lower combustion temperature [18]. This lower temperature would decrease NOx emissions. Another advantage of NG engines is combustion noise compared to gasoline and diesel engines. NG has a slower flame speed than gasoline, so the combustion reaction is lower and generates less noise. Therefore, the compression ratio can be increased to optimize the efficiency of the engine, while generating similar noise comparable to a conventional gasoline engine.

From research done on NG engine models, the combustion noise can be further reduced by advancing ignition timing [19]. From research done between two modern light-duty passenger vehicles, the CNG vehicles exhibited a 3-9\% lower fuel economy than the gasoline vehicle [20]. Even though the CNG engine was modified to increase its compression ratio, the increased flame speed of CNG caused efficiency reduction at medium engine loads. In the modern NG engines in production, several advancements in technologies have been implemented. Gasoline engine downsizing, which was made possible from turbocharging has trickled down into NG engines. In a research study done recently, a turbocharged CNG port fuel injection engine was compared to a gasoline version. From the comparison, the $\mathrm{CNG}$ engine lead to a $24.2 \%$ decrease in $\mathrm{CO}_{2}$ emissions in addition to a $40 \%$ decrease in mileage costs [21]. From a recent analysis done on tractors, it was reported that significant fuel cost savings would be achieved if methane from agricultural waste was utilized instead of diesel fuels based on the market prices in 
2017 [22]. Although the tractor performance utilizing $\mathrm{CH}_{4}$ was comparable to diesel, the fuel capacity was decreased. There is research being done on innovative NG engine technology such as thermochemical fuel reforming [23], but the current technology is not capable of calibrating a proper combustion methodology to optimize the method. However, optimizing emission reductions such as $\mathrm{CO}_{2}$ has shown emission reductions of $25 \%$ [23], when applying current engine technology such as downsizing, EGR, increasing compression ratio and spark time advancing.

\section{Internal Combustion Engine Technology}

Internal combustion engine (ICE) has been recognized as one of the most popular power resource for its high thermal efficiency, reliability and durability. The research on ICE has focused on the improvement in thermal efficiency and the reduction in exhaust emissions. Among all factors affecting the engine thermal efficiency, the heat loss from the hot bulk gas in cylinder to coolant and lubrication oil has been recognized as the one having the most significant impact on engine efficiency [25]. Obtaining a better understanding of the heat transfer in ICE is crucial for the future optimization of ICE. The past research in this area has led to the development of numerous empirical equations calculating the heat loss of on-road diesel and gasoline engine. The latest development of the combined heat and power (CHP) system powered by stationary engine has initiated the interest of accurately estimating the heat loss from large stationary SI engines operated on NG. However, the research for heat loss from off-road SI NG engines has been limited.

Several key research areas are progressing in the ICE field. Several light duty (LD) gasoline concept engines are able to attain up to $18 \%$ reductions in emissions relative to 
conventional engines in production by employing several key technologies such as gasoline direct injection (GDI) and turbocharging [26]. A turbocharger is just an additional component that utilizes the exhaust to generate power for a turbine used to power a compressor capable of boosting the pressure of the intake air. Meanwhile, heavy duty (HD) engines are able to achieve $50 \%$ brake thermal efficiency (BTE) utilizing techniques that are beginning to become commercialized such as complex EGR system and adaptive turbochargers [27]. Research currently indicates that utilizing a supercharger, a turbocharger, specially design piston bowl and complex aftertreatment could reach $55 \%$ BTE [28], which was demonstrated in the Cummins Super Truck [29]. Currently, HD industry achieves an industry average of about $40 \%$ [30]. Nonetheless, the HD NG engines have been increasing in market share. According to the American Public Association Transportation, one-third of all transit buses purchased in the United States in 2012 was CNG buses [31]. As iterated before, the fuel costs savings of switching to NG has been evident in the Lost Angeles (LA) metro buses, where there was a $10-20 \%$ reduction in operational costs for the NG buses compared to diesel buses [32].

\section{Aftertreatment \& Three Way Catalyst}

Efficiency is one of the major focuses of the research and development (R\&D) in the original equipment manufacturers (OEM's), such as Toyota, Cummins, and Volkswagen. In the past decades, the efficiency and the reliability of engines have been continuously improved. According to the Pew Research Institute, the average MPG for automobile engines have doubled in the past three decades [33]. Meanwhile, emissions have decreased almost exponentially, with many modern vehicles emitting ten times less emissions than three 
decades ago. Despite this, the emissions regulations throughout the world are projected to become increasingly stringent in the future. Europe is aiming to include the newly proposed Real Driving Emissions (RDE) particle number regulations, while China and India is aiming to achieve Euro 6 level regulations in the 2020 timeframe [34]. However, extensive improvements on RDE must be achieved before it is finalized. This is especially important in urban and congested areas, emissions from vehicles moving from idle to acceleration exhibit 10 times the emission limit [35], which are not included in the certification or RDE test cycles today. In addition, the regulations of the US Environmental Protection Agency (EPA) has also begun to become increasingly stringent with the possibility of the addition of a $\mathrm{CO}_{2}$ emission standard [36]. The dominant after-treatment systems currently available are the TWC, diesel oxidation catalyst (DOC), diesel particulate filter (DPF), and selective catalytic reduction (SCR). Among these, TWC is the major after-treatment system for SI gasoline and NG engines. TWC is designed to remove harmful pollutants such as NOx, $\mathrm{CO}$ and $\mathrm{HC}$ from the exhaust. The nitrous oxides are converted to harmless nitrogen and carbon dioxide through chemical reactions from the solid catalyst, which is usually platinum or palladium ( $\mathrm{Pd})$. CO is reacted with oxygen resulting in carbon dioxide. Hydrocarbons are reacted with oxygen resulting in water and $\mathrm{CO}_{2}$. In total, there is about fifteen simultaneous reactions occurring as the exhaust passes through the TWC. From a NG engine emissions study utilizing a Pd TWC, resulted in near $100 \% \mathrm{NOx}$ and $80 \% \mathrm{CH}_{4}$ conversion rate [37]. In a laboratory reactor system composed of a TWC tested on a stoichiometric NG engine resulted in near $100 \%$ conversion rates for $\mathrm{CO}, \mathrm{NOx}$ and $\mathrm{CH}_{4}$ emissions [38]. In addition, Cummins recently achieved a breakthrough in oxygen storage capacity (OSC) model, 
which was validated during TWC operation. Basically, this technology improved the efficiency of the TWC during operation by determining the temperature dependence of OSC model with the reductant [39].

\section{Heat Transfer Coefficient}

Calculating the accurate heat release rate (HRR) of an ICE is one of the most complex and challenging problems for all the OEM's. To reiterate, the heat transfer coefficient remains one of the crucial pieces for solving the puzzle of calculating an accurate ICE efficiency. The heat transfer coefficient is a proportionality constant describing the relationship between the heat flux and thermodynamic forces. The main use of this proportionality constant is for calculating the heat transfer from bulk gas to coolant. Researchers utilize the heat transfer coefficient for calculating the heat loss from the engine cylinders over the entire working cycle, which would help improve the calculation of HRR. Despite this, an accurate theoretical approach for heat transfer does not exist. The available methods are composed of an array of theoretical and empirical correlations for heat transfer coefficient calculations. For example, Nusselt [40] was one of the first scientist studied the heat transfer in ICE. After analyzing experimental results, he managed to derive a general equation for the heat transfer coefficient for the cylinders in ICE:

$$
\begin{gathered}
\mathrm{h}=\left(5.388 \times 10^{-4}\right) \cdot\left(1+1.24 \cdot \mathrm{V}_{\mathrm{p}}\right) \cdot \mathrm{T}_{\mathrm{g}}^{\frac{1}{3}} \cdot \mathrm{p}^{\frac{2}{3}}+0.421 \cdot \frac{\left(\mathrm{T}_{\mathrm{g}} / 100\right)^{4}-\left(\mathrm{T}_{\mathrm{W}} / 100\right)^{4}}{\mathrm{~T}_{\mathrm{g}}-\mathrm{T}_{\mathrm{w}}} \text { Eq. (1) } \\
\mathrm{T}_{\mathrm{g}} \& \mathrm{p}=\text { temperature and pressure of working fluid/medium } \\
\mathrm{T}_{\mathrm{W}}=\text { chamber surface temeprature }
\end{gathered}
$$

Utilizing empirical data, Nusselt derived empirical correlations for heat transfer from volume, pressure and temperature. 
However, Eichelberg [41] argued against the additive method that was proposed by Nusselt. Instead, he developed a novel method, which was deduced by the formula below:

$$
\mathrm{h}=77.9 \times 10^{-4} \cdot\left(\mathrm{T}_{\mathrm{g}} \cdot \mathrm{p}\right)^{\frac{1}{2}} \cdot \mathrm{V}_{\mathrm{p}}
$$

Rozenblit [42] used the assumptions of Belinsky [43] that there was radiation heat transfer in engines, to derive another heat transfer coefficient correlation:

$$
\begin{gathered}
\mathrm{h}=\mathrm{C}_{1} \cdot\left(\frac{\mathrm{c}_{\mathrm{u}}}{\mathrm{B}}\right)^{\frac{1}{2}} \cdot\left(\lambda \cdot \mathrm{c}_{\mathrm{p}} \cdot \rho\right)^{\frac{1}{2}} \cdot\left(1+\mathrm{C}_{2} \cdot \frac{\mathrm{a} \cdot \mathrm{W}_{\mathrm{vs}}}{\mathrm{c}_{\mathrm{u}}}\right)+\varepsilon_{\Sigma} \cdot \sigma_{0} \cdot \frac{\mathrm{T}_{\mathrm{p}}^{4}-\mathrm{T}_{\mathrm{W}}^{4}}{\mathrm{~T}_{\mathrm{p}}-\mathrm{T}_{\mathrm{W}}} \\
\mathrm{a}=\left(\mathrm{k} \cdot \mathrm{R} \cdot \mathrm{T}_{\mathrm{g}}\right)^{\frac{1}{2}}-\text { acoustic speed }, \quad \mathrm{C}_{1} \& \mathrm{C}_{2}: \text { empiric coefficients } \\
\mathrm{W}_{\mathrm{vs}}=2.43 \cdot \frac{\mathrm{n} \cdot \mathrm{B}}{\mathrm{k} \cdot \mathrm{p}} \frac{\delta \mathrm{p}}{\delta \varphi} \text { : speed of vibrations }
\end{gathered}
$$

Temperature permeability coefficient: $\zeta=\left(\lambda \cdot c_{p} \cdot \rho\right)^{1 / 2}$

Finally, Woschni [43] developed a correlation for calculating the heat transfer coefficient which became widely used in engine research community. He assumed that the heat transfer was controlled by three factors: convection, radiation and rapid change in gas temperature. By assuming the heat transfer process is quasi-steady, the convection heat transfer coefficient can be calculated by equation:

$$
\begin{gathered}
\mathrm{h}=\alpha \cdot \mathrm{D}^{\mathrm{m}-1} \cdot \mathrm{T}_{\mathrm{g}}^{0.75-1.62 \mathrm{~m}} \cdot \mathrm{p}^{\mathrm{m}} \cdot\left[\mathrm{C}_{1} \cdot \mathrm{V}_{\mathrm{p}}+\mathrm{C}_{2} \cdot \frac{\forall_{\mathrm{d}} \cdot \mathrm{T}_{\mathrm{r}}}{\mathrm{P}_{\mathrm{r}} \cdot \mathrm{V}_{\mathrm{r}}}\left(\mathrm{p}-\mathrm{p}_{0}\right)\right]^{\mathrm{m}} \quad \text { Eq. }(4) \\
\mathrm{m} \text { is the exponential factor given be the relatioship: } \mathrm{Nu}=\mathrm{CRe}^{\mathrm{m}} \\
\alpha \text { : scaling factor } \\
\mathrm{p} \text { : instaneous pressure in cylinder } \\
\mathrm{T}_{\mathrm{g}} \text { : instaneous temperature in the cylinder } \\
\mathrm{p}_{\mathrm{r}}, \mathrm{T}_{\mathrm{r}}, \mathrm{V}_{\mathrm{r}} \text { : reference states at beginning of combustion }
\end{gathered}
$$


$\mathrm{p}_{0}$ : motoring pressure (assuming only compression)

By incorporating the piston speed in the equation, the Woschni equation took into account the swirling of the working medium during combustion. The reference states were taken before combustion takes place. The constants $\mathrm{C}_{1}$ and $\mathrm{C}_{2}$ were set as different value during different phases of the cycle. Therefore, Woschni took these processes into account by specifying specific expressions for calculating the constants at certain phases of the diesel engine cycle.

$$
\begin{gathered}
\text { Compression and Expansion: } \mathrm{U}=2.28 \mathrm{U}_{\text {piston }}, \mathrm{C}_{1}=2.28, \mathrm{C}_{2}=0 \quad \text { Eq. (5) } \\
\mathrm{U}(\mathrm{m} / \mathrm{s}) @ \text { combustion }=2.28 \mathrm{U}_{\mathrm{p}}+0.00324 \mathrm{~T}_{\mathrm{o}} \frac{\mathrm{V}}{\mathrm{V}_{\mathrm{o}}} \frac{\Delta \mathrm{P}_{\mathrm{c}}}{\mathrm{P}_{\mathrm{o}}}, \mathrm{C}_{1}=2.28, \mathrm{C}_{2}=3.24 \cdot 10^{-3} \text { Eq. (6) }
\end{gathered}
$$

By applying the theory of similarity, Woschni accounted for the unsteady heat transfer occurring inside the combustion chamber. This was created by assuming that the flow in the cylinders were similar to the steady flow of a fluid in a pipe. Instead of a pipe, the fluid just flowed through the engine bore, while the average flow velocity was the average speed of the piston. The bulk gas was considered as a uniform working medium. For gasoline engines, the scaling constant was set to be 0.12793 by Woschni [44]. However, the research on NG engines indicates a higher scaling factor. Past research on determining the scaling factors vary for different engines. For diesel compression ignition engines, the scaling factors vary 0.73 based on $\mathrm{HCCl}$ engines [45]. For a 0.9 Liter four stroke SI gasoline engine, the scaling factor was calculated to be 0.82 [46], which was set in most SI models [47]. 


\section{Chapter 3 Experimental Setup}

The engine used was a Wechai, in-line 6-cylinder 9.7 Liter turbocharged SI stoichiometric gaseous fuel engine illustrated in Figure 3-1 below. This off-road engine was designed to operate with a stoichiometric air-fuel mixture. As shown in Table 3-1, the compression ratio was 9.7. The bore was $126 \mathrm{~mm}$ and stroke $130 \mathrm{~mm}$. The fuel mixing and air/fuel ratio control system consists of the following system: (1) IMPCO control system including a variable venturi mixer; (2) Woodward fuel trim valve; (3) Woodward throttle Valve; (4) closed-loop control with Bosch LSU 4.9 wide band UEGO O 2 sensor for pre-catalyst $\mathrm{O}_{2}$ measurement, and Bosch HEGO LSF $4.2 \mathrm{O}_{2}$ sensor for post-catalyst $\mathrm{O}_{2}$ measurement. The premixed fuel entered before the turbocharger. The throttle valve was located upstream of the intake manifold. This engine was developed for off-road operation such as emergency power generation and water pump. All the experimental data was collected and provided by Wechai Power Ltd.

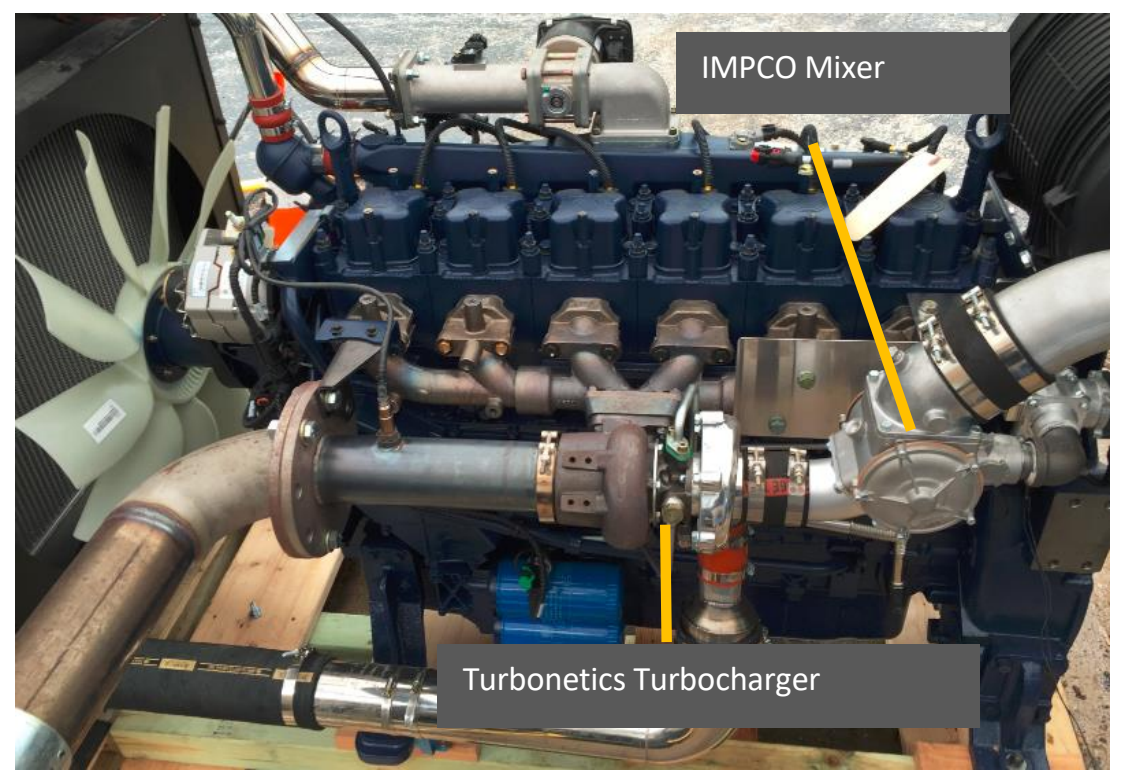

Figure 3-1:WP-10 SI NG Off-Road Engine 
The test engine was coupled to a General Electric Dynamometer Model 42G408A and controlled by a Siemens SIMOREG CM 6RA70 designed to absorb the engine load and control engine speed. The in-cylinder pressure was acquired using a Kistler model $6125 \mathrm{C} 11$ pressure transducer at a $0.5^{\circ}$ crank angle (CA) resolution. A digital data filter was applied to remove the noise of the pressure signal. At each operating point, the cylinder pressure of 200 consecutive cycles was measured, averaged, and processed to obtain the average cylinder pressure which was processed to derive the HRR, heat loss, and a set of combustion parameters. The exhaust gas was sampled for emissions measurement. In this research, the emissions of $\mathrm{CO}$ and $\mathrm{CO}_{2}$ were measured using a non-dispersive infrared (NDIR) analyzer. The emissions of $\mathrm{NO}_{x}$ were measured using a wet chemiluminescence analyzer. The emissions of total hydrocarbon (THC) were measured using a heated flame ionization detector (HFID). The emissions of $\mathrm{CH}_{4}$ were measured using a HFID analyzer equipped with a non-methane cutter. The emissions of non-methane hydrocarbon (NMHC) was calculated by subtracting the $\mathrm{CH}_{4}$ emissions from the $\mathrm{THC}$ emissions.

Table 3-1: Engine Parameters

\begin{tabular}{|c|c|}
\hline Engine type & In-Line, 6-cylinder \\
\hline Engine speed & $1800 \mathrm{rpm}$ \\
\hline Compression ratio & 9.7 \\
\hline Bore & $126 \mathrm{~mm}$ \\
\hline Stroke & $130 \mathrm{~mm}$ \\
\hline Length of Connecting Rod & $216 \mathrm{~mm}$ \\
\hline Power & $175 \mathrm{~kW}$ \\
\hline
\end{tabular}

Table 3-2 presents the higher heating value (HHV) of three fuels examined in this research. The gas chromatograph (GC) analysis to $\mathrm{NG}$ reported a $\mathrm{CH}_{4}$ number of $93.81, \mathrm{H} / \mathrm{C}$ ratio of 3.884, stoichiometric air/fuel ratio of 16.576 . The NG blend Wobbe Index was 49.98 . The first fuel was $100 \% \mathrm{NG}$. The second fuel mixture consisted of $73.4 \% \mathrm{NG}$ and $26.6 \% \mathrm{CO}_{2}$ 
by mass ratio. The last fuel mixture was composed of $54 \% \mathrm{NG}$ and $46 \%$ propane by mass ratio.

Table 3-2: Heating Value of Fuels

\begin{tabular}{|c|c|}
\hline Fuel & HHV, BTU \\
\hline $\mathrm{NG}$ & 1026 \\
\hline $\mathrm{NG}+\mathrm{CO}_{2}$ & 900 \\
\hline $\mathrm{NG}+$ Propane & 1400 \\
\hline
\end{tabular}




\section{Chapter 4 Combustion Analysis and Heat Transfer Model}

\section{Base Heat Release Model}

The gross HRR was calculated using the well-known single zone zero-dimensional heat release model [48]. With the assumptions of a uniform pressure, uniform temperature and ideal gas, the HRR can be calculated using equation (7).

$$
\left[\frac{\mathrm{dQ}}{\mathrm{d} \theta}\right]_{\text {gross }}=\left(\frac{\gamma_{1}}{\gamma_{1}-1}\right) \cdot \mathrm{P} \cdot \frac{\mathrm{dV}}{\mathrm{d} \theta}+\left(\frac{1}{\gamma_{1}-1}\right) \cdot \mathrm{V} \cdot \frac{\mathrm{dp}}{\mathrm{d} \theta} \quad \text { Eq. (7) }
$$

$\gamma_{1}$ is the specific heat ratio for method 1. By utilizing the log of pressure and volume, the specific heat ratio for exhaust and intake is determined. Evidently, this type of practice leads to a specific heat ratio, which includes the heat loss. However, it lacks accuracy for calculating the heat loss during combustion, since it approximates zones of the combustion process of an ICE.

$$
\left[\frac{\mathrm{dQ}}{\mathrm{d} \theta}\right]_{\text {gross }}=\left(\frac{\gamma_{2}}{\gamma_{2}-1}\right) \cdot \mathrm{P} \cdot \frac{\mathrm{dV}}{\mathrm{dt}}+\left(\frac{1}{\gamma_{2}-1}\right) \cdot \mathrm{V} \cdot \frac{\mathrm{dp}}{\mathrm{dt}}+\left[\frac{\mathrm{dQ}}{\mathrm{d} \theta}\right]_{\text {heat transfer }}
$$

$\gamma_{2}$ is the specific heat ratio calculated for method 2. In the industry, the specific heat ratio is calculated from the net heat release equation in Heywood without the heat transfer term [48]. In contrast, the specific heat ratio in method 2 is implemented for calculating the gross heat release based on the composition and temperature of the bulk mixture. Then, it is evaluated using the ideal gas equation with the in-cylinder pressure and volume at the intake valve closing as a reference condition. Therefore, it contains the additional heat transfer term as shown in equation (8).

In this research, the specific ratio $Y$ of the bulk mixture was calculated by examining the specific heat under constant volume equation (9): 


$$
\overline{\mathrm{c}}_{\mathrm{v}, \text { mix }}=\sum \mathrm{X}_{\mathrm{i}} \cdot \overline{\mathrm{c}}_{\mathrm{v}, \mathrm{i}} \quad \text { Eq. (9) }
$$

Where: $X_{i}$ is the molar fraction; $c_{v, i}$ is the specific heat ratio under constant volume calculated utilizing the equation:

$$
\begin{gathered}
\text { (Specific Heat Value) } \mathrm{C}_{\mathrm{p}}^{\mathrm{o}}=\mathrm{A}+\mathrm{B} \cdot \mathrm{T}+\mathrm{C} \cdot \mathrm{T}^{2}+\mathrm{D} \cdot \mathrm{T}^{3}+\frac{\mathrm{E}}{\mathrm{T}^{2}} \text { Eq. (10) } \\
\text { (Standard Enthalpy) } \mathrm{H}^{\mathrm{o}}-\mathrm{H}_{298.15}^{\mathrm{o}}=\mathrm{A} \cdot \mathrm{T}+\frac{\mathrm{B}}{2} \cdot \mathrm{T}^{2}+\frac{\mathrm{C}}{3} \cdot \mathrm{T}^{3}+\frac{\mathrm{D}}{4} \cdot \mathrm{T}^{4}-\frac{\mathrm{E}}{\mathrm{T}}+\mathrm{F}-\mathrm{H} \text { Eq. (11) }
\end{gathered}
$$

\section{T: temperature of the mixture}

The constants for the calculation of the specific heat under constant can be found in the appendix. This data was derived from the calculating the trend line utilizing the data on specific heat for each of the selected species based on the data provided by National Institute of Standards and Technology (NIST).

\section{Estimation of Bulk Gas Temperature at Intake Valve Closing}

The bulk gas temperature was estimated from calculating the residual and fresh mass intake at intake valve closing. This was achieved by calculating the mass per cycle for the fuel and air.

$$
\mathrm{m}_{\text {intake }}=\frac{\mathrm{m}_{\text {fuel1 }}}{\frac{0.5^{\mathrm{o}}}{12 \cdot \mathrm{v}_{\text {engine }}} \cdot \mathrm{n}_{\text {cylinders }}}\left(\frac{\mathrm{kg}}{\text { cycle }}\right) \text { Eq. }
$$

The total fresh mass was calculated per cycle.

$$
\mathrm{m}_{\text {fresh }}=\mathrm{m}_{\text {air }}+\sum_{\mathrm{n}=1}^{\infty} \mathrm{m}_{\text {fuel } 1,2 \ldots \mathrm{n}}+\sum_{\mathrm{n}=1}^{\infty} \mathrm{m}_{\text {intake addition } 1,2 \ldots \mathrm{n}} \quad\left(\frac{\mathrm{kg}}{\text { cycle }}\right) \text { Eq. }
$$

The residual mass per cycle was calculated from ideal gas equation utilizing the pressure at bottom dead center and minimum volume based on the initial data. 


$$
\mathrm{m}_{\text {residual }}=\frac{\mathrm{P}_{\mathrm{BDC}} \cdot \mathrm{V}_{\mathrm{IVC}}}{\mathrm{R}_{\text {mixture }} \cdot \mathrm{T}_{\text {exhaust }} \cdot \mathrm{n}_{\text {cylinders }}}\left(\frac{\mathrm{kg}}{\text { cycle }}\right) \mathrm{E}
$$

Then, the cycle interval time was determined from the RPM data and crank angle data.

Utilizing the mass flow rate equilibrium, the initial temperature was calculated.

$$
\mathrm{T}_{\text {initial }}=\mathrm{T}_{\mathrm{g}}+\frac{\left(\frac{\mathrm{m}_{\text {residual }}}{\mathrm{m}_{\text {fresh }}}\right) \cdot\left(\mathrm{T}_{\text {exhaust }}+273.15\right)}{\left(1+\frac{\mathrm{m}_{\text {residual }}}{\mathrm{m}_{\text {fresh }}}\right)} \text { (K) Eq. (15) }
$$

\section{Calculation of Bulk Mixture Temperature and Pressure}

The intake mass was calculated from ideal gas equation. The percentage mass fraction was calculated for each of the species for each fuel mixture.

$$
\begin{gathered}
\% \mathrm{MF}_{\text {fresh }}=(1-\mathrm{MFB}) \cdot \mathrm{m}_{\text {initial species }} \cdot \mathrm{m}_{\text {fresh }} / \mathrm{M}_{\text {species }} \text { Eq. (16) } \\
\% \mathrm{MF}_{\text {residual }}=\mathrm{m}_{\text {final species }} \cdot \mathrm{m}_{\text {residual }} / \mathrm{M}_{\text {species }} \text { Eq. (17) } \\
\% \mathrm{MF}_{\text {final }}=\mathrm{MFB} \cdot \mathrm{m}_{\text {final species }} \cdot \mathrm{m}_{\text {fresh }} / \mathrm{M}_{\text {species }} \text { Eq. (18) }
\end{gathered}
$$

The enthalpy was calculated for each species.

$$
\sum \mathrm{H}_{\mathrm{r}}=\mathrm{x}_{\text {initial species }} \cdot\left[\left(\mathrm{h}_{\mathrm{f}}^{\mathrm{o}}\right)_{\mathrm{i}}+\Delta \mathrm{h}_{\mathrm{i}}\right]_{\text {initial species }} \text { Eq. (19) }
$$

Utilizing the gas Shomate equations, the specific heat under constant volume were calculated.

$$
\mathrm{C}_{\mathrm{v}: \text { Burn,Residual,Fresh }}=\sum \% \mathrm{MF}_{\text {Burn,Residual,Fresh }} \cdot \mathrm{C}_{\mathrm{v} \text { : Species }}\left(\frac{\mathrm{kJ}}{\mathrm{kmol} \cdot \mathrm{K}}\right) \text { Eq. (20) }
$$

Furthermore, the gas constant for each of the specific gas species were calculated. Then, the specific heat ratio was calculated utilizing:

$$
\gamma_{2}=\frac{c_{p}}{c_{p}-R_{u}} \text { Eq. (21) }
$$


Then, the specific heat ratio calculated in equation (21) is applied to equation (8) to calculated the gross heat release rate.

\section{Calculation of Heat Loss}

The heat transfer coefficient was determined by the Woschni equation:

$$
\begin{gathered}
\mathrm{h}=\alpha \cdot \mathrm{D}^{\mathrm{m}-1} \cdot \mathrm{T}_{\mathrm{g}}^{0.75-1.62 \mathrm{~m}} \cdot \mathrm{p}^{\mathrm{m}} \cdot\left[\mathrm{C}_{1} \cdot \mathrm{V}_{\mathrm{p}}+\mathrm{C}_{2} \cdot \frac{\mathrm{V}_{\mathrm{d}} \cdot \mathrm{T}_{\mathrm{r}}}{\mathrm{P}_{\mathrm{r}} \cdot \mathrm{V}_{\mathrm{r}}}\left(\mathrm{p}-\mathrm{p}_{0}\right)\right]^{\mathrm{m}} \\
\mathrm{m}=0.8 \text { (standard value for SI engine) }
\end{gathered}
$$

$\alpha$ is the scaling factor that is iterated to a value to accurately calculate the heat transfer coefficient. Then, the heat transfer coefficient is applied to calculate the heat loss as demonstrated in many other experiments [50].

$$
\Delta \mathrm{Q}_{\text {loss }}=\mathrm{h} \cdot \mathrm{A} \cdot\left(\mathrm{T}_{\mathrm{g}}-\mathrm{T}_{\mathrm{W}}\right) \cdot \Delta \mathrm{t} \quad \text { Eq. (23) }
$$

The net heat release was calculated using the equation recommended by Heywood [48]. The gross heat release was calculated from the addition of the heat loss.

$$
\left[\frac{\mathrm{dQ}}{\mathrm{d} \theta}\right]_{\text {gross }}=\left[\frac{\mathrm{dQ}}{\mathrm{d} \theta}\right]_{\text {net }}+\left[\frac{\mathrm{dQ}}{\mathrm{d} \theta}\right]_{\text {heat transfer }} \text { Eq. (24) }
$$

The molecular weight was calculated at each step to maintain accuracy of the mixture and to re-calculate the specific gas constant at each step. Then, the temperature at the $\mathrm{n}^{\text {th }}$ step was determined from the ideal gas equation.

$$
\mathrm{T}_{\mathrm{n}}=\frac{\left\{[\Delta \mathrm{Q}]_{\text {gross }}-\Delta \mathrm{W}\right\}}{\mathrm{m}_{\text {intake }} \cdot \mathrm{C}_{\mathrm{v} \text { of fuel +air }}}+\mathrm{T}_{\mathrm{n}-1} \text { Eq. (25) }
$$

This process was iterated to create the entire heat release and pressure curve. The iteration was designed to minimize percentage error between the cylinder pressure measured and heat release rate before and after combustion. 


$$
\mathrm{P}_{\text {calc }}=\frac{\mathrm{R}_{\text {specific }} \cdot \mathrm{T}_{\mathrm{n}} \cdot \mathrm{m}_{\text {intake }}}{\forall} \text { Eq. (26) }
$$

The enthalpy balance was applied with low heating value of the fuel to determine the simulation results were within the limits of the theoretical maximum of the heat release curve.

$$
\mathrm{Q}_{\text {in }}=\mathrm{Q}_{\text {Gross }}=\sum \mathrm{H}_{\mathrm{p}}-\sum \mathrm{H}_{\mathrm{r}}=\eta_{\text {combustion }} \cdot \mathrm{m}_{\mathrm{f}} \cdot \mathrm{Q}_{\mathrm{LHV}} \text { Eq. (27) }
$$

\section{Assumptions}

There are a few crucial assumptions for this model, which would lead to error between the actual measurements:

1) The combustion reaction burns completely based on the basic stoichiometric equations for each of the fuel mixtures. Lean and rich combustion is not taken into account throughout the process.

2) It is assumed there is no blowby, which would lead to higher error post-combustion for the calculations.

3) Assumes the temperature of the cylinder wall remains at $400 \mathrm{~K}$, which will lead to error for the heat loss calculations.

4) The fuel mixtures in the cylinder acts as an ideal gas, which allows it to be approximated by the ideal gas equation.

5) Based on the Woschni equation, the intake, combustion and exhaust periods are set at specific crank angles. However, in a real engine, the values would differ based on which are the definitions utilized, which would have to be calibrated to maintain accuracy. 


\section{Comparison}

Figure 4-1 shows the cylinder pressure of this engine operated with pure NG observed at spark timing (ST) $22.5^{\circ} \mathrm{CA}$ BTDC. The peak cylinder pressure measured was 76.2 bar, which was observed at $13^{\circ} \mathrm{CA}$ ATDC. This current pressure curve shown was the average of 200 engine operation cycles.

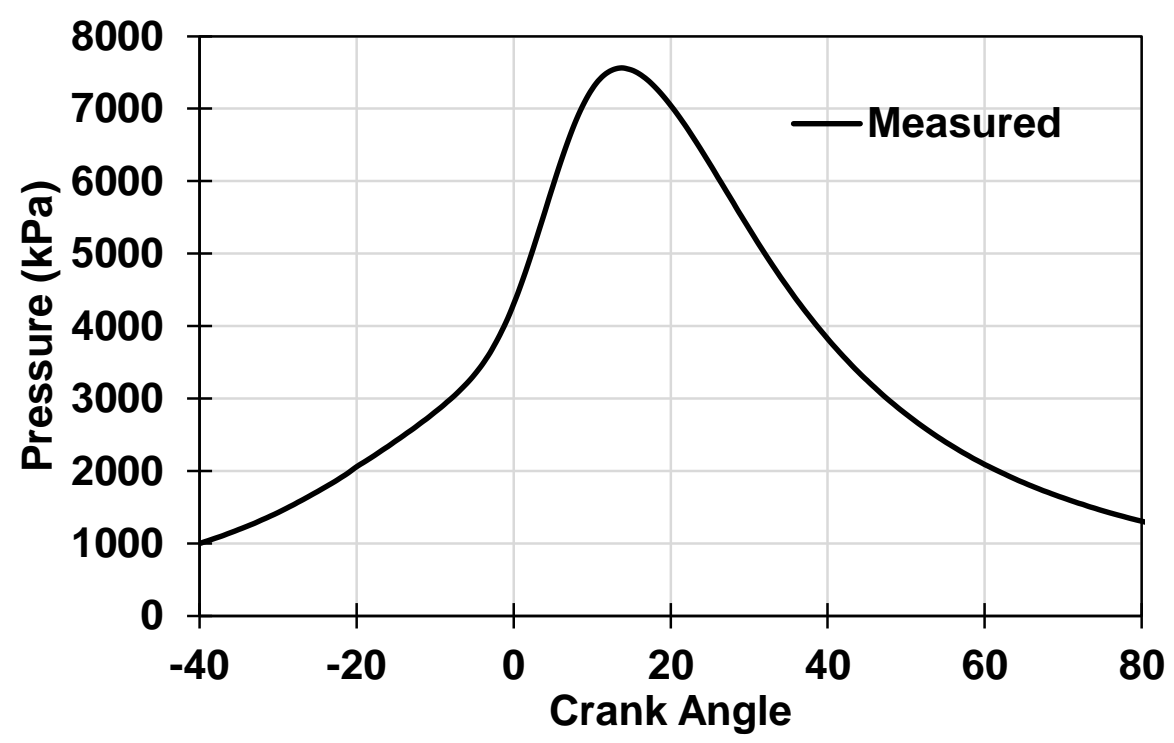

Figure 4-1: Cylinder Pressure Data, Fuel: NG. ST: $22.5^{\circ}$ CA BTDC

Currently, the industries utilize a simpler and less theoretical method to calculate the heat release of the fuel during combustion process, which will be referred to as method 1 . It involves determining the polytropic gas constant during post-combustion and precombustion sections of the log pressure vs log volume graph from the engine pressure data. This gives two average specific values, one is utilized for the pre-combustion phase and the other one is utilized to calculate the post-combustion phase heat release. As shown in Figure 4-2, the post-combustion polytropic constant is 1.3163 and the polytropic compression process constant during the pre-combustion is 1.346 . Applying the industry utilized method, the heat loss is assumed to be averaged throughout the periods, which generally leads to an underestimation. 


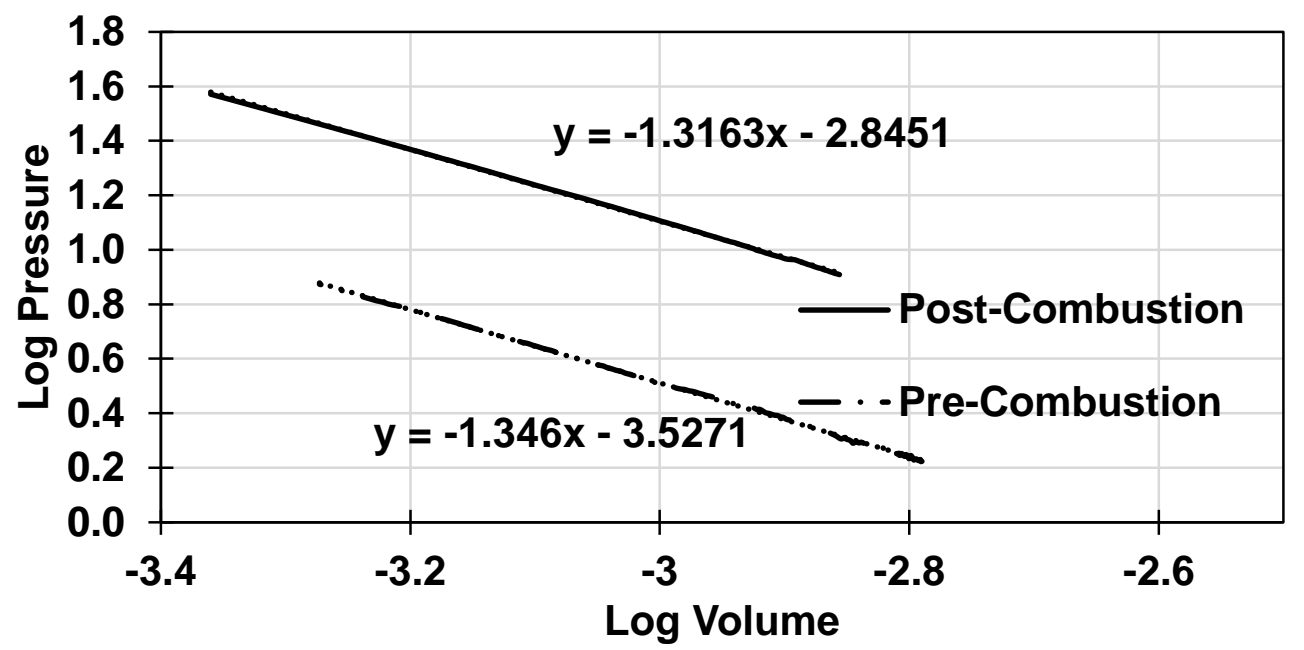

Figure 4-2: Industry Method for Specific Heat Ratio Calculations Fuel: NG ST: $22.5^{\circ} \mathrm{CA}$ BTDC

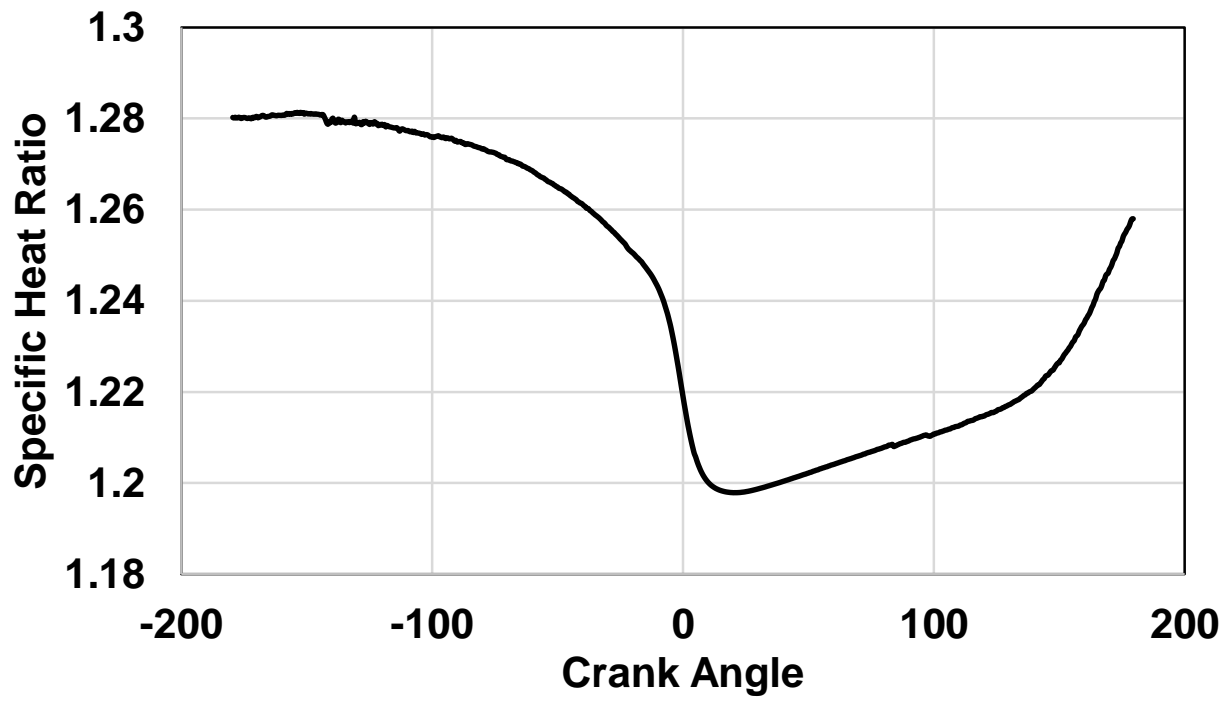

Figure 4-3: Specific Heat Ratio Variation, Fuel: NG, ST: $22.5^{\circ}$ CA BTDC

Utilizing the Gas Shomate equation coefficients provided by the NIST, a more accurate specific heat ratio was calculated and applied to determining the heat release of the combustion process of this SI engine. This technique will be referred as method 2. As shown in Figure 4-3, the specific heat ratio drops from 1.28 to 1.20 as combustion occurs, but slowly recovers as the temperature drops. As demonstrated in Figure 4-4, 
method 2 yields a significantly higher gross heat release rate than the industry's log comparison method.

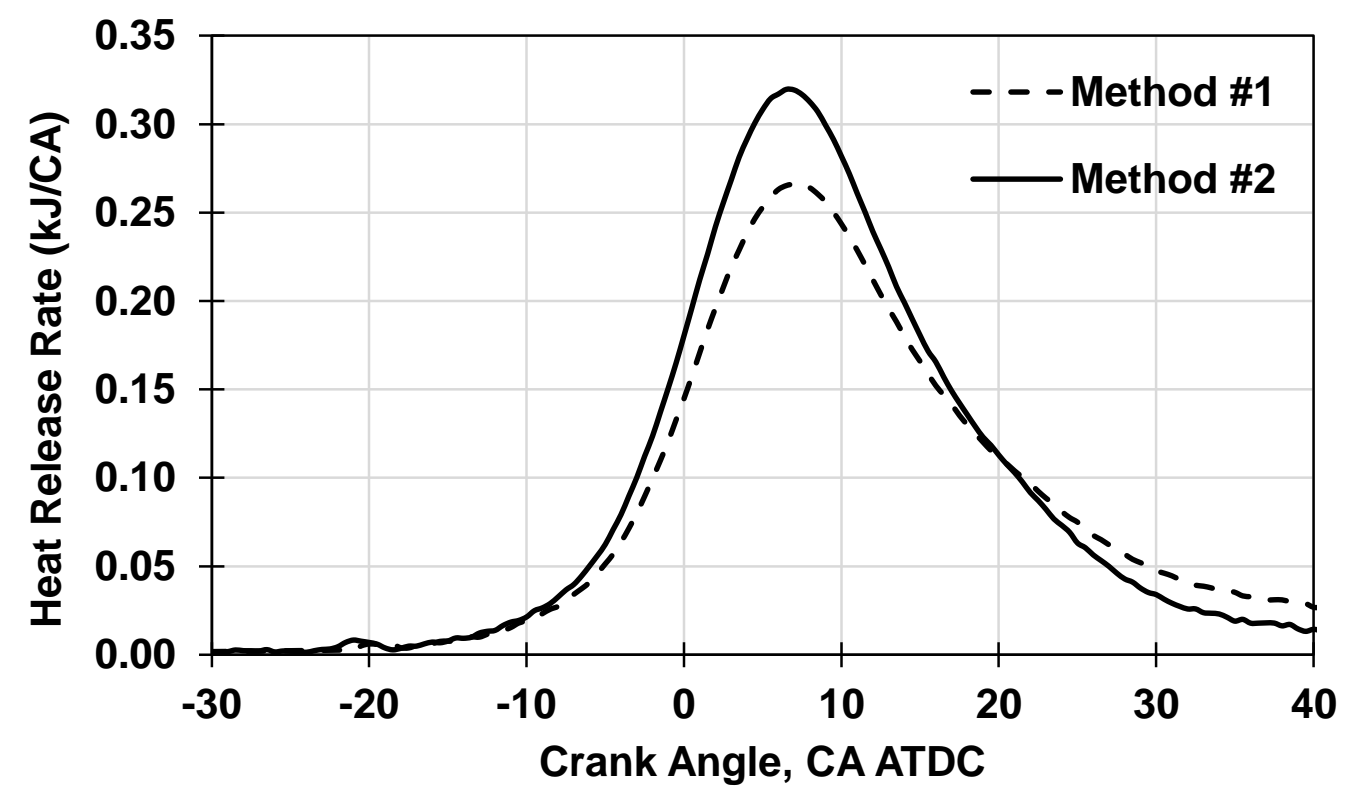

Figure 4-4: Industry Calculated Gross Heat Release Rate Vs. Woschni Calculated Gross Heat Release Rate, Fuel: NG. ST: $22.5^{\circ}$ CA BTDC

As illustrated in Figure 4-5 below, the combustion process calculated using Method 2 proceeds slightly faster than that calculated using Method 1 during early combustion stage but at a much slower rate during late combustion stage. Such a difference may be due to the increased heat loss calculated during late combustion stage. This is backed up by the heat release data, where it shows method 1 crossing the heat release curve of method 2 during the latter part of post-combustion phase. 


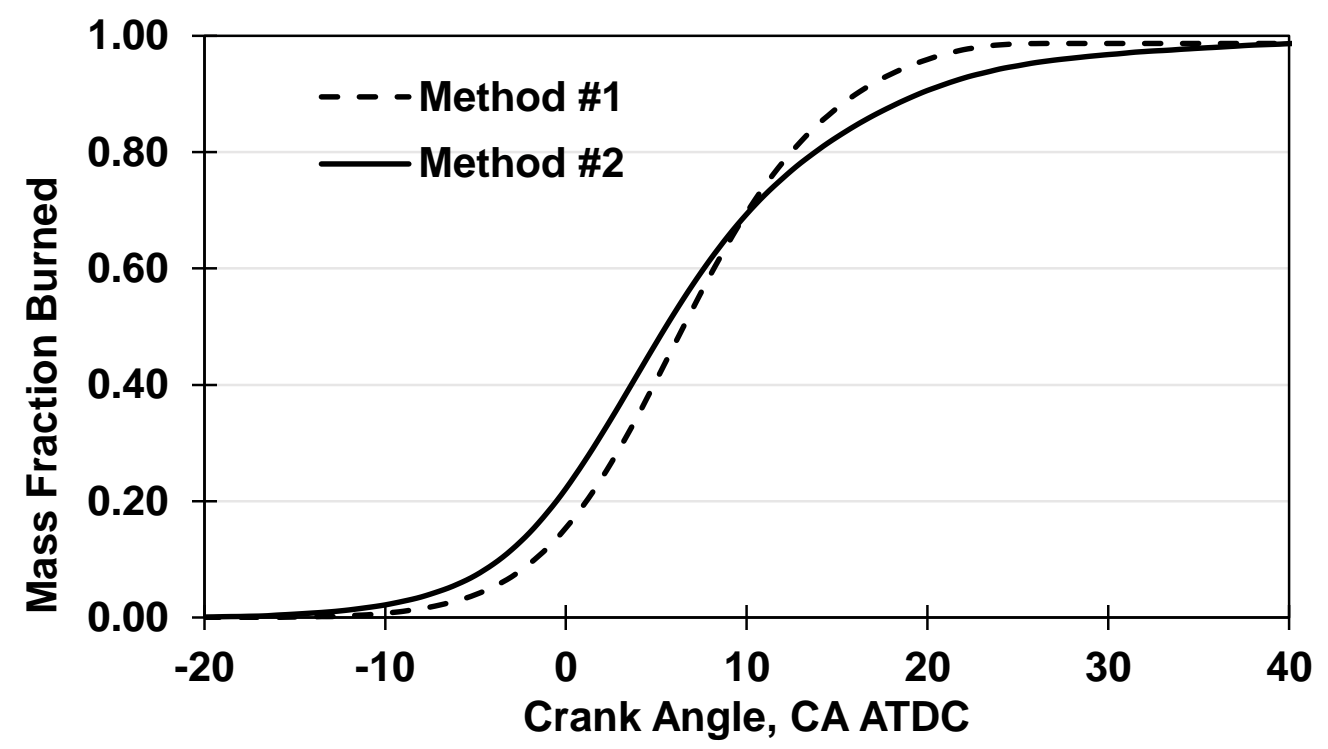

Figure 4-5: Mass Fraction Burned Comparison. Fuel: NG. St: 20.5 CA BTDC

\section{Validation}

There were two types of methods to validate the model. The first method utilized was pressure comparison. As demonstrated in Figure 4-6 below, both of the measure and calculated pressure data are in close proximity with each other.

The percentage error between the measured pressure data and the calculated pressure data observed during the pre-combustion compression process before spark timing (ST) ranges from $0.1-1.8 \%$. Assuming the combustion occurs during spark timing and ends after the mass fraction burned achieves $100 \%$, the error between the pressure measured and simulated during the combustion expansion process ranges from $0.98-1.41 \%$. Assuming that the post-combustion phase involves the period after the Woschni equation assumed the exhaust period began, the difference between the measured pressure data and the calculated pressure data ranges about $2.13-2.84 \%$. 


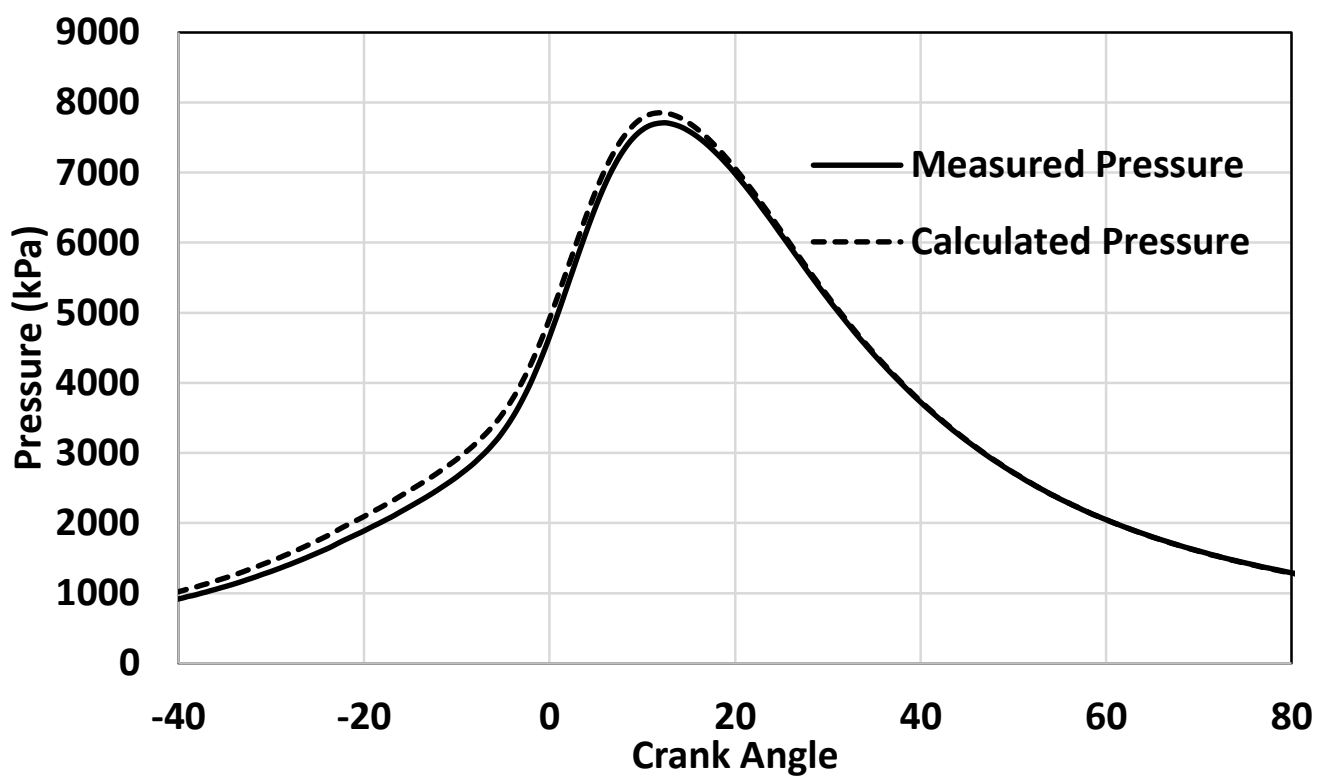

Figure 4-6: Measured and Calculated Pressure Utilizing Woschni Heat Release Equation, Release Rate, Fuel: NG. ST: $22.5^{\circ} \mathrm{CA}$ BTDC

Table 4-1: Percent Error between Calculated and Measured Pressure

\begin{tabular}{|c|c|c|c|c|c|c|c|c|c|}
\hline Spark Timing & -22.5 & -20.5 & -18.5 & -22.5 & -20.5 & -18.5 & -22.5 & -20.5 & -18.5 \\
\hline \#Run & 1492 & 1493 & 1494 & 1500 & 1501 & 1502 & 1510 & 1511 & 1512 \\
\hline Type of Fuel & \multicolumn{3}{|c|}{ Natural Gas } & \multicolumn{3}{|c|}{ Natural Gas $+\mathrm{CO}_{2}$} & \multicolumn{3}{|c|}{ Natural Gas + Propane } \\
\hline $\begin{array}{l}\text { Pre-Combustion } \\
\text { Avg. Pressure } \\
\text { Difference }\end{array}$ & $1.56 \%$ & $1.09 \%$ & $1.59 \%$ & $1.71 \%$ & $1.16 \%$ & $1.74 \%$ & $0.19 \%$ & $0.40 \%$ & $1.14 \%$ \\
\hline $\begin{array}{l}\text { Combustion } \\
\text { Avg. Pressure } \\
\text { Difference }\end{array}$ & $1.44 \%$ & $1.40 \%$ & $1.38 \%$ & $1.40 \%$ & $1.34 \%$ & $1.34 \%$ & $0.98 \%$ & $0.97 \%$ & $1.31 \%$ \\
\hline $\begin{array}{c}\text { Post- } \\
\text { Combustion } \\
\text { Avg. Pressure } \\
\text { Difference }\end{array}$ & $2.74 \%$ & $2.84 \%$ & $2.57 \%$ & $2.54 \%$ & $2.65 \%$ & $2.37 \%$ & $2.31 \%$ & $2.13 \%$ & $2.60 \%$ \\
\hline
\end{tabular}

This data is shown for all three fuel mixtures in Table 4-1, where the measured and calculated data is compared. From the table, it is evident that the combustion modelling utilizing method 2 is on average $1 \%$ more accurate for pre-combustion to combustion phase than post combustion phase. This is understandable because for post-combustion, since 
the blowby is not accounted for in the pressure calculations, there will be higher deviation from the measured data. Comparing the different mixture of fuels, there does not seem to be a trend in the inaccuracy of the data.

Table 4-2: Heat Release Rate Validation

\begin{tabular}{|l|c|c|c|c|c|c|c|c|c|}
\hline Spark Timing & -22.5 & -20.5 & -18.5 & -22.5 & -20.5 & -18.5 & -22.5 & -20.5 & -18.5 \\
\hline \#Run & 1492 & 1493 & 1494 & 1500 & 1501 & 1502 & 1510 & 1511 & 1512 \\
\hline $\begin{array}{l}\text { Type of Fuel } \\
\text { Natural Gas }\end{array}$ & \multicolumn{3}{|c|}{ Natural Gas $+\mathrm{CO}_{2}$} & \multicolumn{2}{|c|}{ Natural Gas + Propane } \\
\hline $\begin{array}{l}\text { Pre-Combustion } \\
\text { HRR (kJ) }\end{array}$ & 0.002 & 0.002 & 0.002 & 0.002 & 0.002 & 0.002 & 0.001 & 0.002 & 0.002 \\
\hline $\begin{array}{l}\text { Post-Combustion } \\
\text { HRR (kJ) }\end{array}$ & - & -0.018 & -0.018 & -0.018 & -0.018 & -0.018 & -0.009 & -0.018 & -0.018 \\
\hline
\end{tabular}

The second type of method utilized was by iterating to verify that the heat release rate before and after combustion should be zero. Then, the scaling factor of the Woschni equation was iterated by increments of 0.01 to determine the lowest value approaching to $0 \mathrm{~kJ}$ from the calculated heat released during pre and post combustion. This data is shown in the Table 4-2 below. As demonstrated, the calculated gross heat release was less than the theoretical maximum, which demonstrated that the results were valid. From the comparison shown in Table 4-3, it is evident that method 2, which utilizes a temperature derived specific heat ratio yields a significantly higher net HRR.

Table 4-3: Net HRR Comparison

\begin{tabular}{|c|c|c|c|c|c|c|c|c|c|}
\hline Spark Timing & -22.5 & -20.5 & -18.5 & -22.5 & -20.5 & -18.5 & -22.5 & -20.5 & -18.5 \\
\hline \#Run & 1492 & 1493 & 1494 & 1500 & 1501 & 1502 & 1510 & 1511 & 1512 \\
\hline Type of Fuel & \multicolumn{3}{|c|}{ Natural Gas } & \multicolumn{3}{c|}{ Natural Gas + CO2 } & \multicolumn{3}{c|}{ Natural Gas + Propane } \\
\hline $\begin{array}{c}\text { Net HRR } \\
\text { Method 1(kJ) }\end{array}$ & 4.726 & 4.688 & 4.837 & 4.723 & 4.722 & 4.749 & 4.575 & 4.604 & 4.602 \\
\hline $\begin{array}{c}\text { Net HRR } \\
\text { Method 2 (kJ) }\end{array}$ & 5.679 & 5.746 & 5.806 & 5.764 & 5.862 & 5.940 & 5.711 & 5.701 & 5.786 \\
\hline
\end{tabular}


As illustrated in the Table 4-4 below, there is a slight trend of a lower heating value results in a lower scaling factor. The scaling factor for the NG and propane mixture were the lowest. The scaling factor for NG remained the highest throughout the entire test.

Table 4-4: Calculated Woschni Coefficients for Fuels

\begin{tabular}{|l|c|c|c|}
\hline Fuel & Natural Gas & Natural Gas $+\mathrm{CO}_{2}$ & Natural Gas + Propane \\
\hline Woschni Scaling Factor & 0.34 & 0.33 & 0.32 \\
\hline
\end{tabular}




\section{Chapter 5 Combustion Process of SI Turbo Natural Gas Engine}

This chapter examines the effect of fuel composition and spark timing on the combustion process and exhaust emissions. The heat release rate was calculated using Method 2. The heat loss was calculated using the revised Woschni equation with the scaling factor derived in Chapter 4. The heat release rate was further processed to derive the variation of the mass fraction burned with changes in crank angle, and a set of combustion parameters such as CA5, CA10, CA50, CA90, and CA95 representing the crank angle location at which the corresponding percentage of combustion energy has been released.

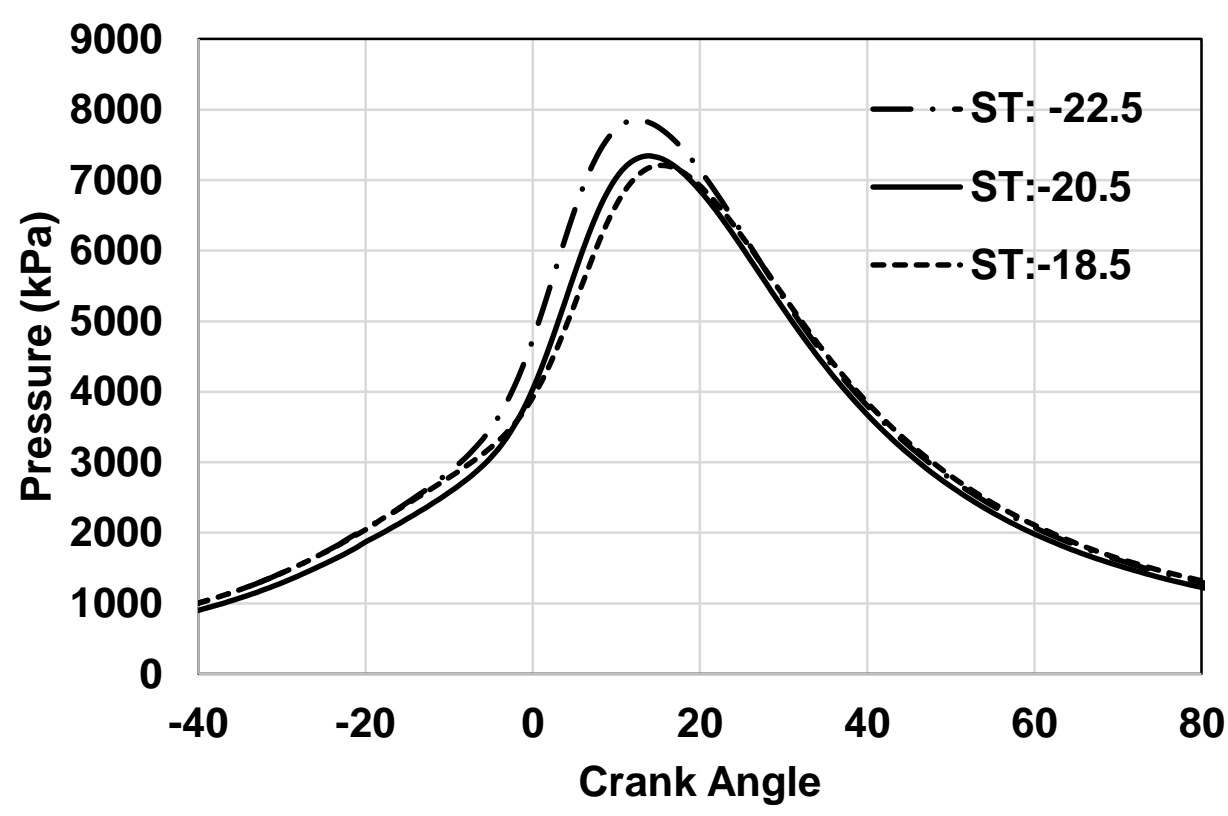

Figure 5-1: The effect of spark timing on cylinder pressure. Fuel: NG

As shown in Figure 5-1, advancing the spark timing increased the peak cylinder pressure if it is earlier from BTDC. The peak pressure observed at spark timing $22.5^{\circ} \mathrm{CA}$ BTDC was 78.54 bar while at $18.5^{\circ} \mathrm{CA}$ BTDC was 72.07 bar. This represented almost a $9 \%$ decrease in peak cylinder pressure due to a difference of only four crank angle. This is the same for the heat release rate as shown in figure 5-2 below. The peak heat release rate at ST of $22.5^{\circ} \mathrm{CA}$ BTDC was $0.3874 \mathrm{~kJ} /{ }^{\circ} \mathrm{CA}$ while at $18.5^{\circ} \mathrm{CA}$ BTDC was $0.3674 \mathrm{~kJ} /{ }^{\circ} \mathrm{CA}$. This 
represented a $5.5 \%$ decrease in peak gross heat release rate due to a difference of only four crank angle.

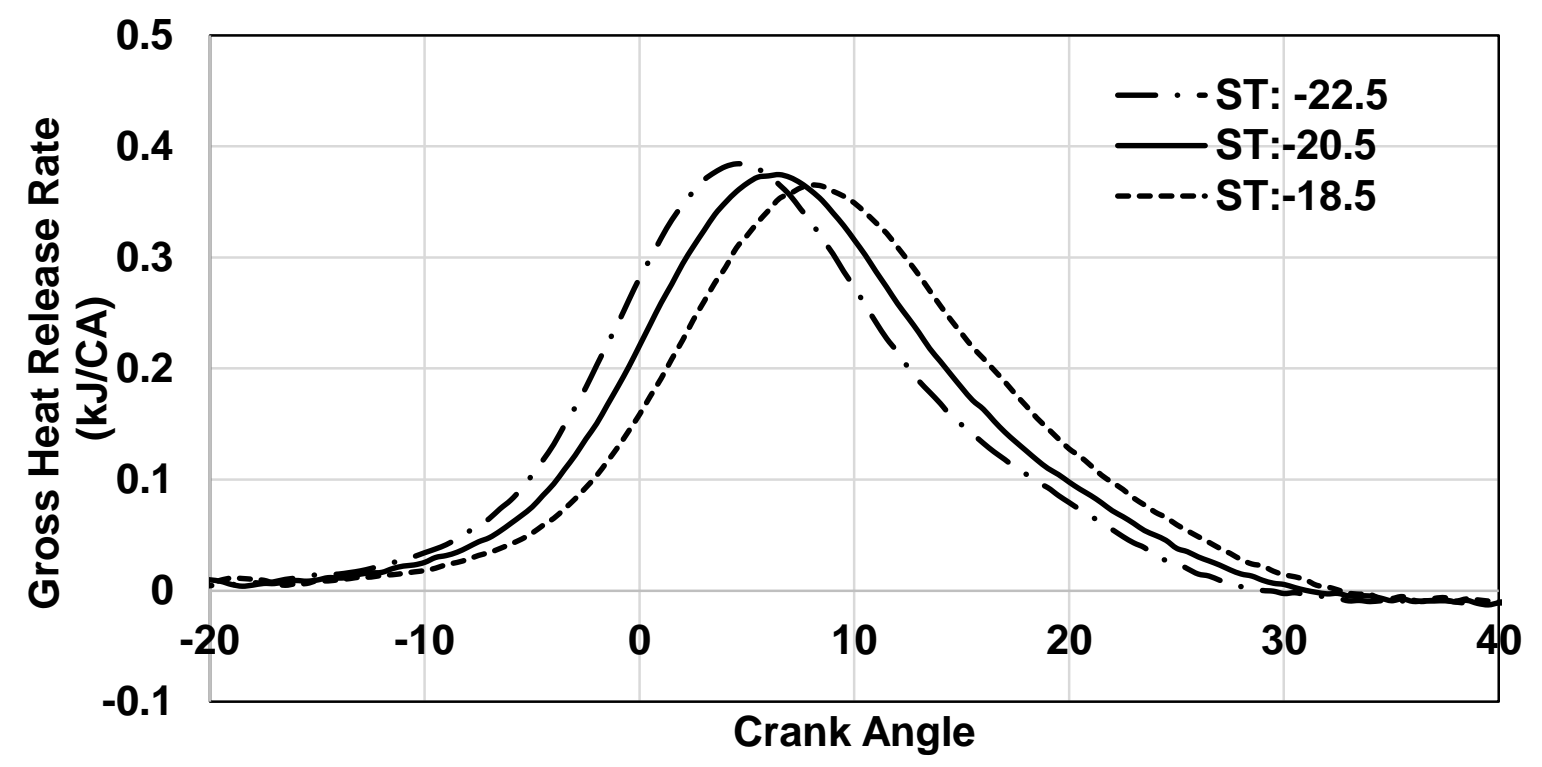

Figure 5-2: The effect of spark timing on gross heat release. Fuel: NG

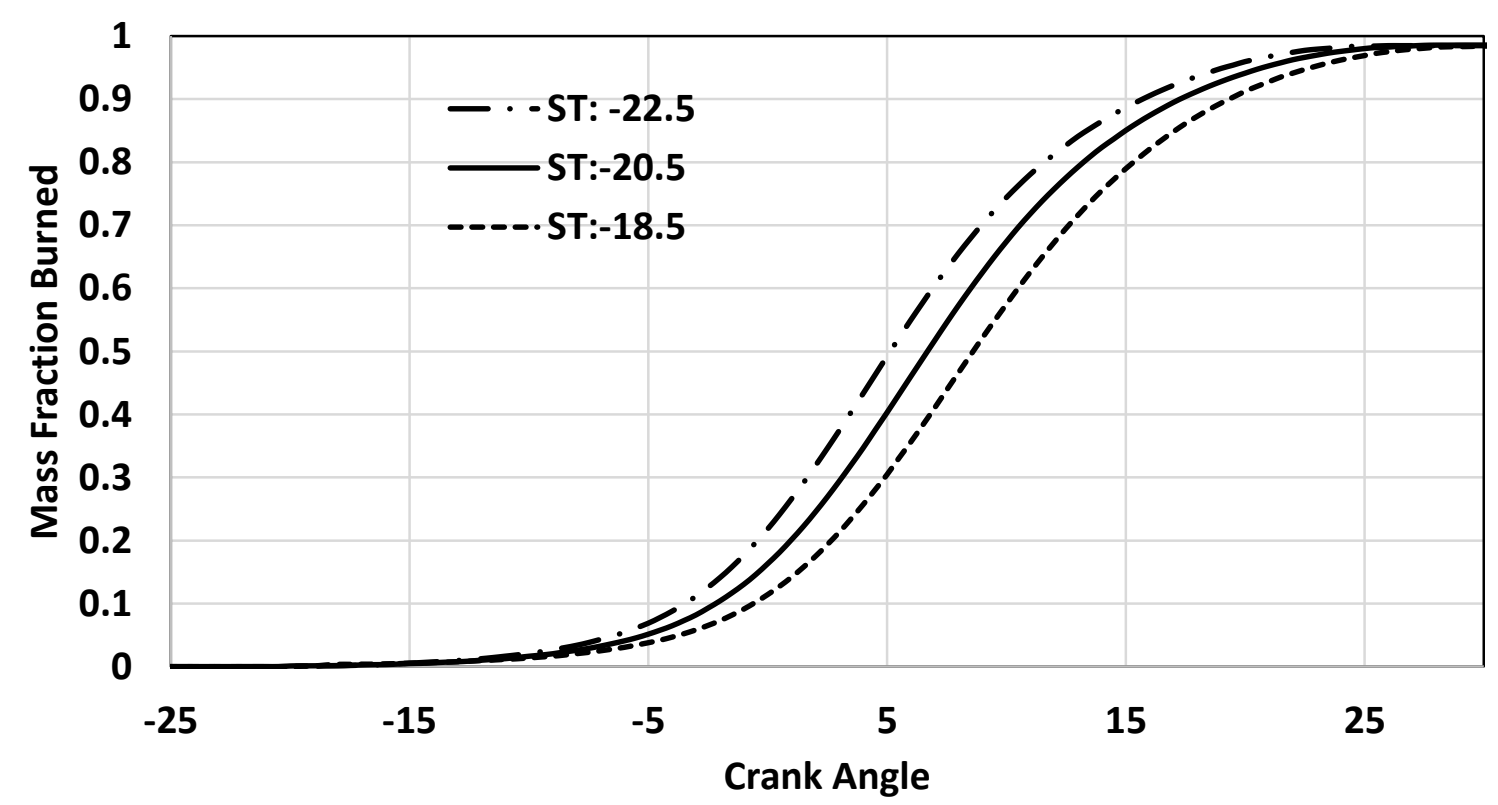

Figure 5-3: The effect of spark timing on mass fraction burned. Fuel: NG 
As demonstrated in Figure 5-3, advancing spark timing leads to a delayed mass fraction burned. This is emphasized in Table 5-1, where it is evident that as the spark timing is set closer to TDC, the ignition delay is increased and the combustion duration is increased. Therefore, although there was not as significant difference compared to the pressure data, it is noticeable, which emphasizes the importance of the spark timing for combustion analysis.

Table 5-1: Spark Timing Impact on Combustion Phasing, Fuel: NG

\begin{tabular}{|c|c|c|c|}
\hline Type of Fuel & \multicolumn{3}{|c|}{ Natural Gas } \\
\hline Spark Timing & -22.5 & -20.5 & -18.5 \\
\hline CA5 & -7.74 & -6.60 & -5.14 \\
\hline CA10 & -4.49 & -3.24 & -1.64 \\
\hline CA50 & 3.86 & 5.40 & 7.35 \\
\hline CA90 & 10.59 & 12.33 & 14.59 \\
\hline CA95 & 11.83 & 13.58 & 15.90 \\
\hline
\end{tabular}

Figure 5-4 below compares the cylinder pressure of this engine operated at three fuels. Adding propane increased the peak cylinder pressure from 75.6 bar to 80.0 bar. The propane and NG mixture generated the highest peak cylinder pressure due to propane's higher flame speed, which would speed up the combustion process. The addition of $\mathrm{CO}_{2}$ decreased the peak pressure by about $250 \mathrm{kPa}$. This is understandable, since the excess $\mathrm{CO}_{2}$ would be taking up some of the space of the intake air, which would hamper combustion and yield a lower heat release rate and peak pressure. 


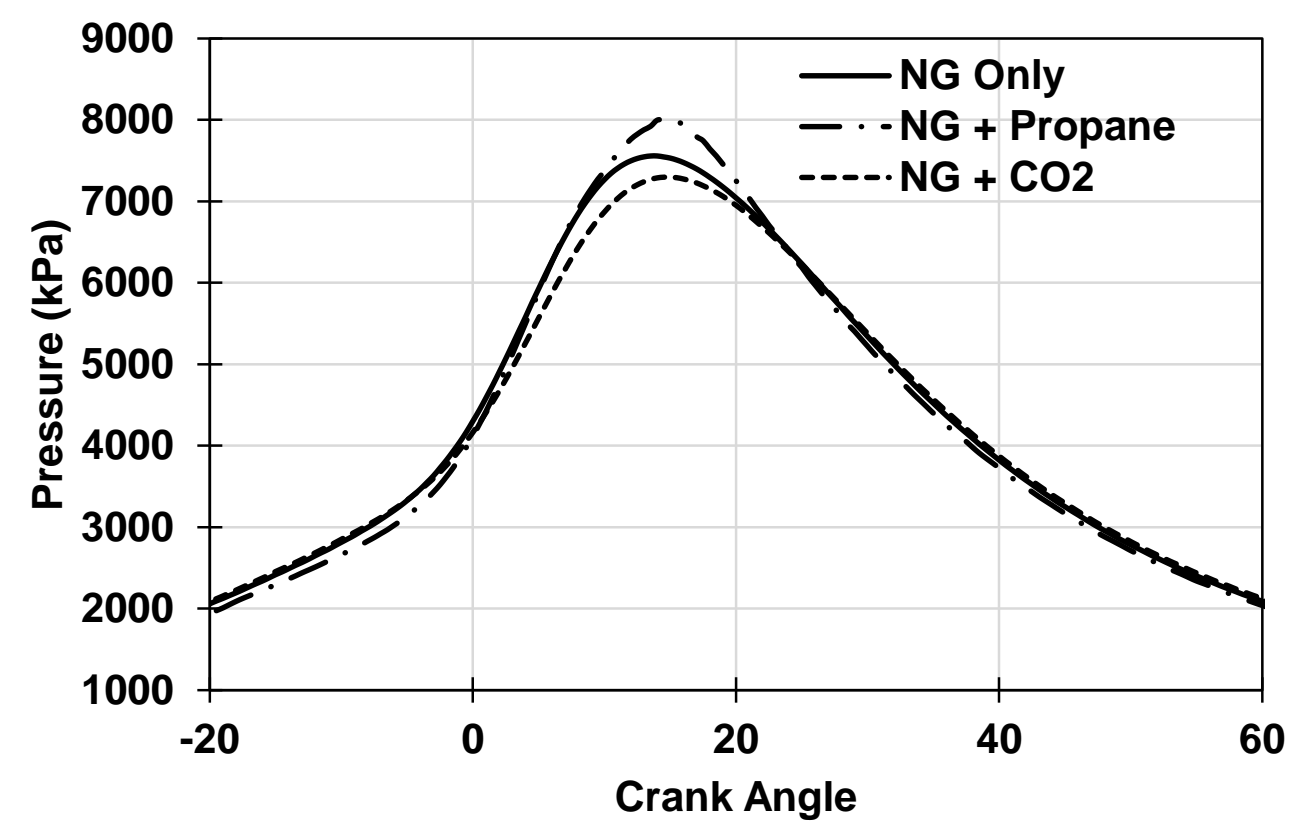

Figure 5-4:The effect of fuel composition on cylinder pressure. $\mathrm{NG}, \mathrm{NG}+\mathrm{CO}_{2}$ and $\mathrm{NG}+$ Propane, ST: $20.5^{\circ} \mathrm{CA}$ BTDC

The three different fuel mixtures are compared in Figure 5-5. The peak heat release rate observed with $\mathrm{NG}+$ Propane mixture was $0.4141 \mathrm{~kJ} /{ }^{\circ} \mathrm{CA}$, which was $9.6 \%$ higher compared to $0.3778 \mathrm{~kJ} /{ }^{\circ} \mathrm{CA}$ observed with $\mathrm{NG}$ as fuel. The peak heat release rate observed with the addition of $\mathrm{CO}_{2}$ to $\mathrm{NG}$ was $0.3523 \mathrm{~kJ} /{ }^{\circ} \mathrm{CA}$ or $6.75 \%$ lower than $\mathrm{NG}$ due to decelerated flame propagation rate, and slightly retarded combustion phasing as shown in Figure 5-4. The fast flame propagation of NG and propane mixture as fuel was also supported by the mass fraction burned shown in Figure 5-7. 


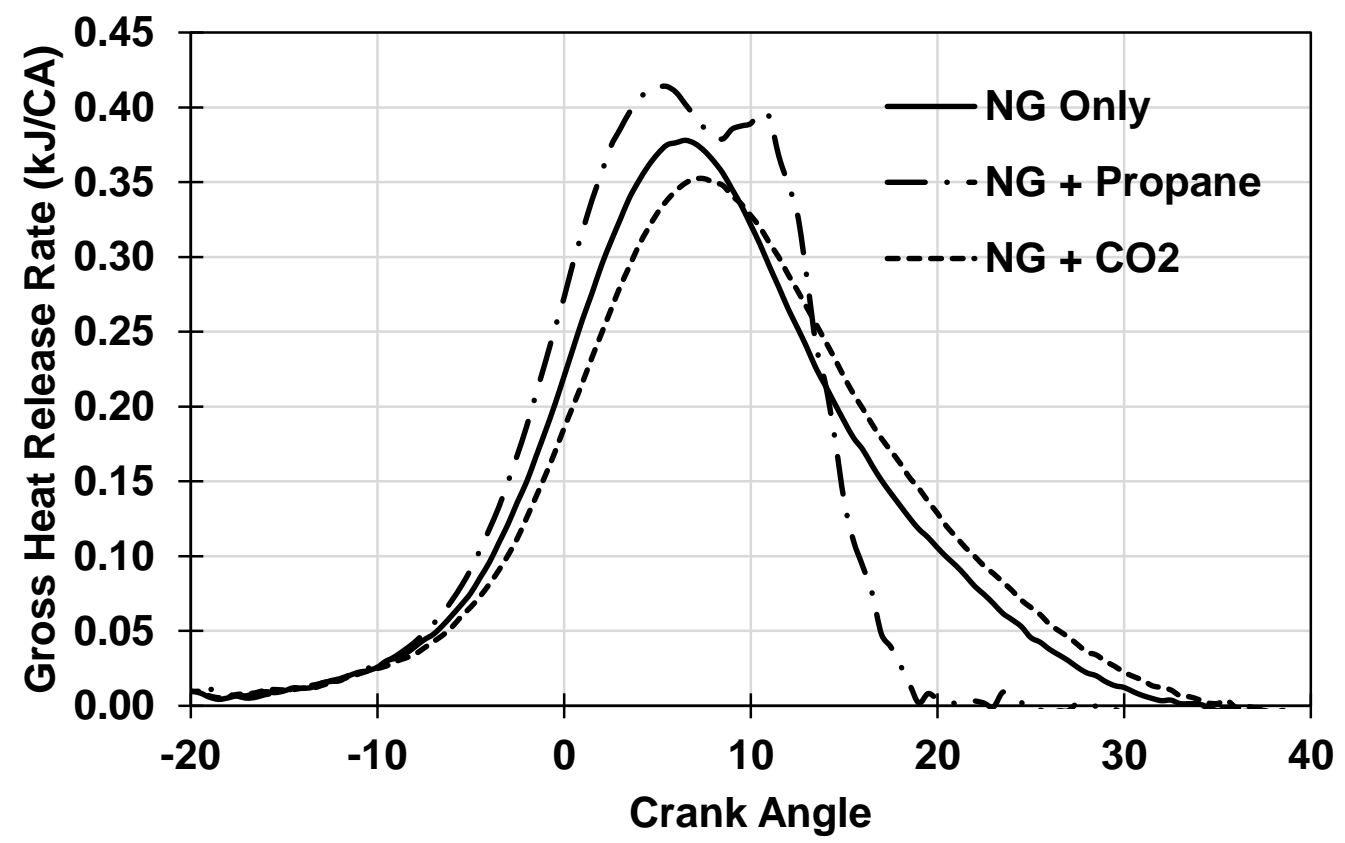

Figure 5-5: The effect of fuel composition on gross heat release rate, ST: $20.5^{\circ} \mathrm{CA}$ BTDC

Utilizing method 2, the heat loss was calculated as shown in Figure 5-6 for all three fuel mixtures at ST of $20.5^{\circ} \mathrm{CA}$ BTDC. The highest peak heat loss was from NG and propane, which was $0.0085 \mathrm{~kJ} /{ }^{\circ} \mathrm{CA}$. The lowest peak heat loss was from $\mathrm{NG}$ and $\mathrm{CO}_{2} 0.0074 \mathrm{~kJ} /{ }^{\circ} \mathrm{CA}$. The peak heat loss for $\mathrm{NG}$ remains between the three mixtures at $0.0077 \mathrm{~kJ} /{ }^{\circ} \mathrm{CA}$. Furthermore, the heat loss calculated from the Woschni equation represents about $15 \%$ of the total heat released as shown in Table 5-2 below, which is in line with past research [49].

Table 5-2: Total Heat Loss

\begin{tabular}{|c|c|c|c|c|c|c|c|c|c|}
\hline Spark Timing & -22.5 & -20.5 & -18.5 & -22.5 & -20.5 & -18.5 & -22.5 & -20.5 & -18.5 \\
\hline Type of Fuel & \multicolumn{3}{|c|}{ Natural Gas } & \multicolumn{3}{c|}{ Natural Gas + CO2 } & \multicolumn{3}{c|}{$\begin{array}{c}\text { Natural Gas + } \\
\text { Propane }\end{array}$} \\
\hline $\begin{array}{c}\text { Heat Loss } \\
\text { (Method 2, kJ) }\end{array}$ & 1.014 & 0.994 & 0.966 & 0.982 & 0.964 & 0.941 & 0.962 & 0.952 & 0.951 \\
\hline
\end{tabular}




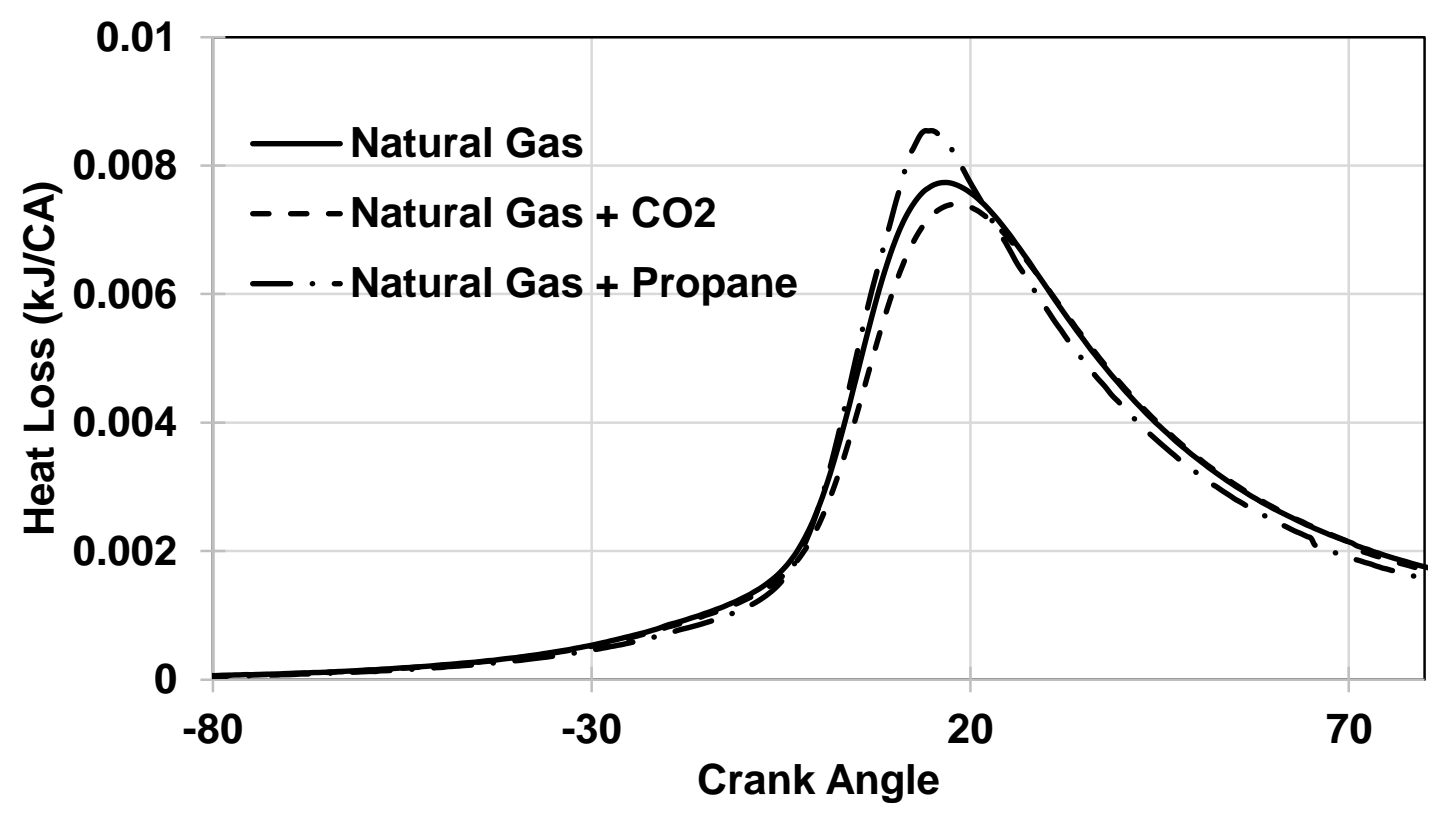

Figure 5-6: The effect of fuel composition in heat loss. ST: $20.5^{\circ} \mathrm{CA}$ BTDC

As shown in Table 5-3, there is significant fuel impact for combustion phasing. Utilizing the values from Table 5-3 to calculate the combustion parameters of combustion phasing. The ignition delay is defined as the difference between ST and CA5. The fast combustion duration is defined as the difference between CA90 and CA10. The combustion duration is the difference between CA95 and CA5.

Table 5-3: Fuel Impact On Combustion Phasing. ST: $20.5^{\circ} \mathrm{CA}$ BTDC

\begin{tabular}{|c|r|r|r|r|r|}
\hline Fuel & CA5 & CA10 & CA50 & CA90 & CA95 \\
\hline $\mathrm{NG}$ & -6.60 & -3.24 & 5.40 & 12.33 & 13.58 \\
\hline $\mathrm{NG}+\mathrm{CO}_{2}$ & -6.23 & -2.65 & 6.60 & 14.14 & 15.50 \\
\hline $\mathrm{NG}+$ Propane & -6.96 & -3.88 & 4.01 & 9.68 & 10.39 \\
\hline
\end{tabular}


Table 5-4: Fuel Composition Impact on Ignition Delay \& Combustion Duration for Different Fuel Mixtures. ST: $20.5^{\circ} \mathrm{CA}$ BTDC

\begin{tabular}{|c|c|c|c|}
\hline Fuel & Ignition delay, CA & Fast comb. Duration, CA & Comb. Duration, CA \\
\hline $\mathrm{NG}$ & 13.90 & 15.58 & 20.18 \\
\hline $\mathrm{NG}+\mathrm{CO}_{2}$ & 14.27 & 16.79 & 21.72 \\
\hline $\mathrm{NG}+$ Propane & 13.54 & 13.56 & 17.36 \\
\hline
\end{tabular}

As shown in Table 5-4, the fuel mixture of NG and propane had the shortest ignition delay relative to the other fuels based on the same spark timing. From the gross heat release graph and the table given, the combustion ended significantly earlier than NG fuel by itself. As expected, the addition of $\mathrm{CO}_{2}$ increased both the ignition delay and the combustion duration.

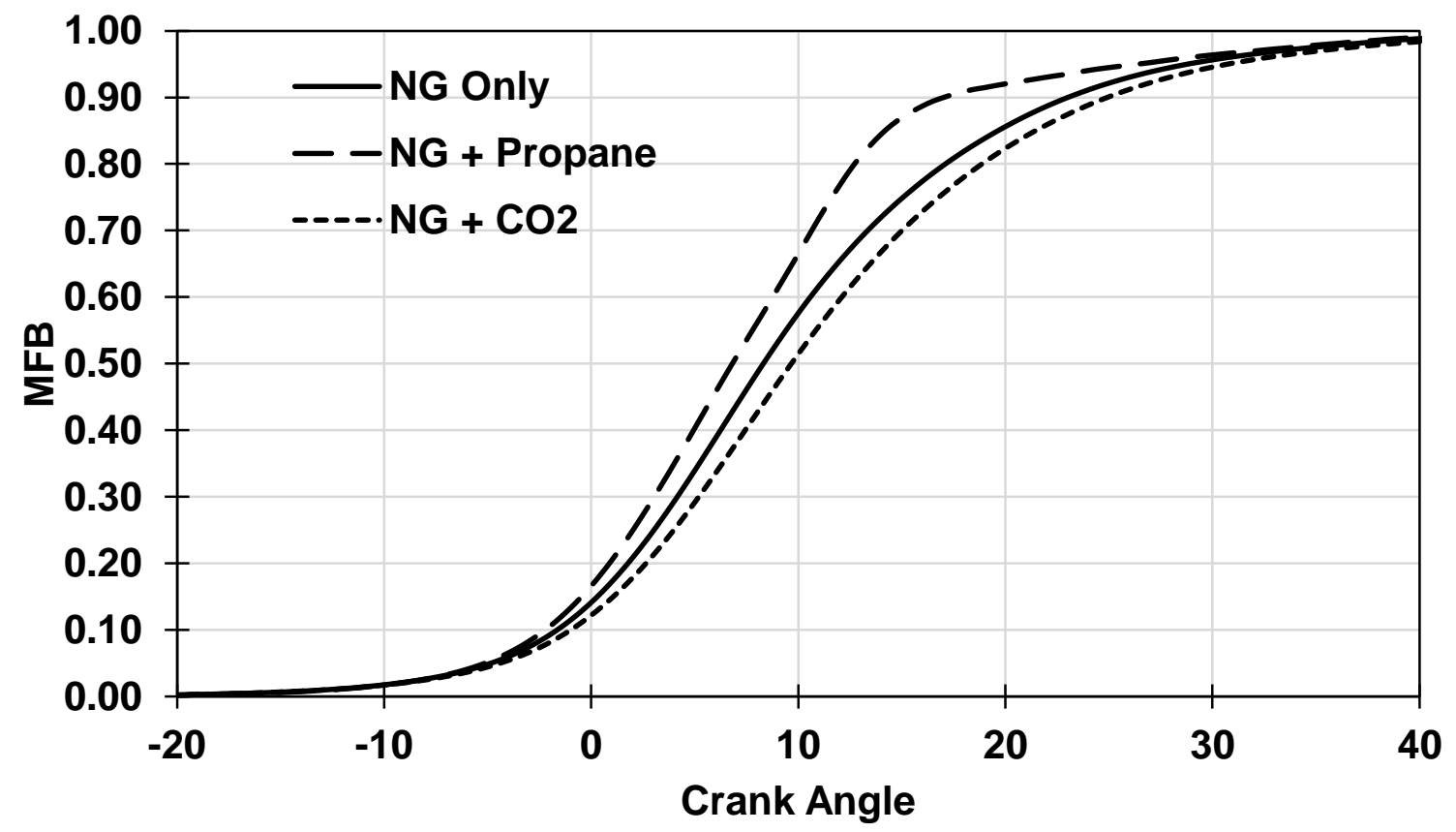

Figure 5-7: The effect of fuel composition in mass fraction burned. ST: $-22.5^{\circ}$ CA BTDC 
As illustrated in Figure 5-7 propane has a signification initial mass fraction burn due to its high flame propagation. However, as all three mixtures approach $100 \%$, the mass fraction progress narrows together. With $\mathrm{CO}_{2}$ hampering the combustion process, it is expected that the $\mathrm{NG}$ and $\mathrm{CO}_{2}$ mixture has the lowest mass fraction burn of all three fuels examined. The results obtained in this work also suggests that blending propane to low BTU gases may provide an effective approach of adjusting the heating value of available gaseous fuels for better combustion in SI gaseous fuel engines. The approach effectively utilizes the higher heating value and faster flame propagation rate of propane and high octane number of low BTU gases to further increase the brake thermal efficiency as higher compression ratio can be utilized. These concepts may also off-set the seasonal variation in the quality and quantity of low BTU gaseous produced in landfill and digester in wastewater treatment plants. Table 5-5 shows the engine-out emissions of $\mathrm{CO}_{2}, \mathrm{NO}_{x}, \mathrm{CO}, \mathrm{CH}_{4}$, and $\mathrm{UMHC}$.

Table 5-5: Engine Out Emissions. ST: $20.5^{\circ} \mathrm{CA}$ BTDC. Unit: g/bhp-hr.

\begin{tabular}{|c|c|c|c|}
\hline Fuel & NG Only & $\mathrm{NG}+$ Propane & $\mathrm{NG}+\mathrm{CO}_{2}$ \\
\hline $\mathrm{CO}_{2}{ }^{*}$ & 426.9 & 466.91 & $411.13^{*}$ \\
\hline $\mathrm{NO} \times$ & 11.75 & 13.01 & 12.79 \\
\hline $\mathrm{CO}$ & 8.01 & 8.80 & 5.79 \\
\hline $\mathrm{THC}$ & 0.52 & 0.47 & 0.51 \\
\hline $\mathrm{NMHC}$ & 0.07 & 0.25 & 0.09 \\
\hline$\eta_{\text {combustion }}$ & $98.15 \%$ & $98.10 \%$ & $98.8 \%$ \\
\hline
\end{tabular}

${ }^{*} \mathrm{CO}_{2}$ added to intake fuel was not accounted as exhaust emissions NG yields the lowest $\mathrm{NO}_{x}$ emissions, which is about $10 \%$ lower than other two fuels. The lowest $\mathrm{CO}_{2}$ emissions were observed when operated at $\mathrm{NG}+\mathrm{CO}_{2}$. This is due to the best brake thermal efficiency observed with $\mathrm{NG}+\mathrm{CO}_{2}$ as shown in Table 5-4. In addition, the brake specific carbon monoxide emissions were $10-20 \%$ lower for the $\mathrm{NG}+\mathrm{CO}_{2}$ mixture. 
The advantage of the propane and NG mixture is the THC emissions, which is 10 to $15 \%$ lower than the THC emissions observed with other two fuel candidates. Nonetheless, all the brake specific emissions are before the after-treatment system, so therefore as long as the effectiveness of the after-treatment system is high enough, the engine will still be in compliance with the standards. The emissions of $\mathrm{CO}_{2}$, hydrocarbon, and $\mathrm{CO}$ were further processed to derive the combustion efficiency defined as the percentage of carbon in fuel converted to $\mathrm{CO}_{2}$. As shown in Table 5-6, the combustion efficiency calculated was $98.10 \%$ to $98.8 \%$ indicating the extent of complete combustion of gaseous fuel burned this engine.

Table 5-6: After-Treatment Out Exhaust Emissions. (g/bhp-hr) ST: $20.5^{\circ} \mathrm{CA}$ BTDC

\begin{tabular}{|c|c|c|c|}
\hline Fuel & $\begin{array}{c}\mathrm{NG} \\
\text { Only }\end{array}$ & $\begin{array}{c}\mathrm{NG}+ \\
\text { Propane }\end{array}$ & $\begin{array}{c}\mathrm{NG}^{+} \\
\mathrm{CO}_{2}\end{array}$ \\
\hline $\mathrm{CO}$ & 0.7031 & 0.6426 & 0.7573 \\
\hline $\mathrm{NO} \times$ & 0.0504 & 0.0162 & 0.0594 \\
\hline $\mathrm{NMHC}$ & 0.0034 & 0.0047 & 0.0040 \\
\hline $\mathrm{THC}$ & 0.0252 & 0.0170 & 0.0125 \\
\hline
\end{tabular}

Table 5-7: Exhaust Emissions and Regulations of EPA and CARB, g/bhp-hr

\begin{tabular}{|c|c|c|}
\hline Fuel & $\mathrm{NO}_{x}+\mathrm{NMHC}$ & $\mathrm{CO}$ \\
\hline $\mathrm{NG}$ & 0.0538 & 0.7031 \\
\hline $\mathrm{NG}+\mathrm{CO}_{2}$ & 0.0634 & 0.7573 \\
\hline $\mathrm{NG}+$ Propane & 0.0209 & 0.6426 \\
\hline EPA Regulation & 2.02 & 3.29 \\
\hline CARB Regulation & 0.75 & 3.28 \\
\hline
\end{tabular}

*Voluntary

Table 5-7 compares if the emissions are in compliance with the current emission regulations applied by EPA and CARB. The emissions measured after the triple way catalyst were substantially lower than the emission regulations. Utilizing the most advanced TWC after-treatment system applied to the SI NG engines, the current emissions standards 
is achievable on all three types of gaseous fuels. As shown in Table 5-6, for the current $\mathrm{CO}, \mathrm{THC}, \mathrm{NO}_{x}$ and $\mathrm{NMHC}$ emissions, the engine is in compliance with both EPA and CARB regulations. The CO emissions are well below the $3.28 \mathrm{~g} / \mathrm{bhp}-\mathrm{hr}$ level [36]. The THC and $\mathrm{NMHC}$ emissions follow the same pattern. In addition, this engine operated on three fuels are also in compliance with California's voluntary $\mathrm{NO}_{x}+\mathrm{NMHC}$ emissions levels [36]. This demonstrates that commercial application of the NG engine is feasible currently, as long as more research and development is completed. 


\section{Chapter 6 Small Engine Instrumentation}

For continuing research on the heat transfer model, a small engine was modified for investigating exhaust emissions and combustion process analysis. The objective of the small engine research was to investigate the effect of fuel on the combustion and exhaust emissions from a small SI engine of the research on the heat transfer for small NG engines. The engine was a 3500 Watt Champion Model 46597 Gasoline Electric Generator photographed in the Figure 6-1 below.

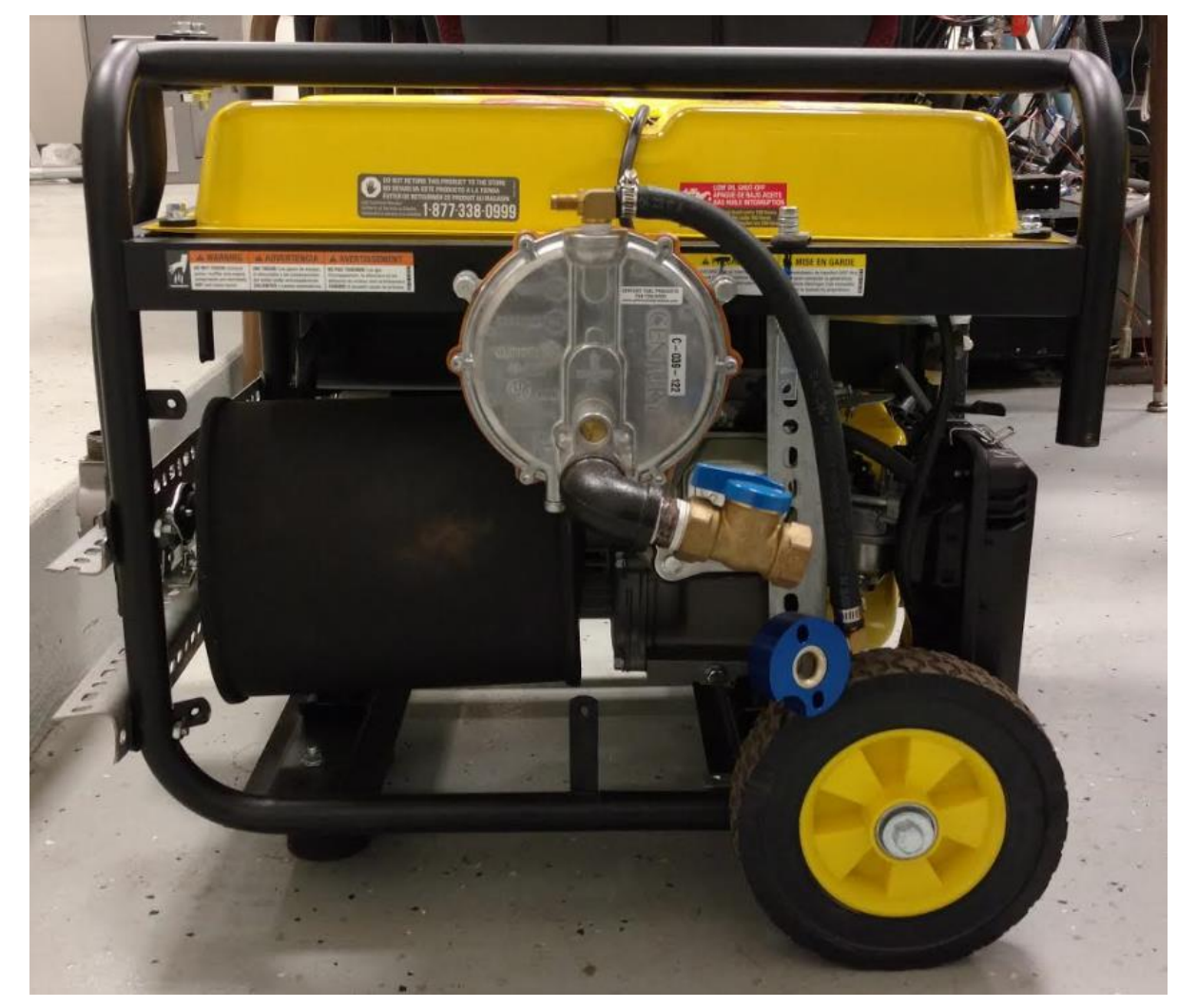

Figure 6-1: 3500W Champion Electric Generator

It had a $196 \mathrm{cc}$ single cylinder OHV engine. The generator contained a 3.8-gallon tank, which was capable of operating for 12 hours at $50 \%$ load. The pressure transducer that placed into the engine was a high temperature pressure sensor, Kistler 6056A. 
However, due to the engine cylinder size, a sleeve was utilized for mounting the pressure sensor to insure a more stable and tighter fit as shown in Figure 6-2. The sleeve was designed utilizing a 3/8" bolt. A $4.4 \mathrm{~mm}$ drill bit was utilized for the entire length of the hole, while a $6.25 \mathrm{~mm}$ drill bit was utilized for the top section of the transducer sleeve. Afterwards, a 5.0 drill tap was utilized for the mid-section of the sleeve to produce the thread for the pressure transducer to lock in. This design provided a compact and secure fit for the pressure transducer.
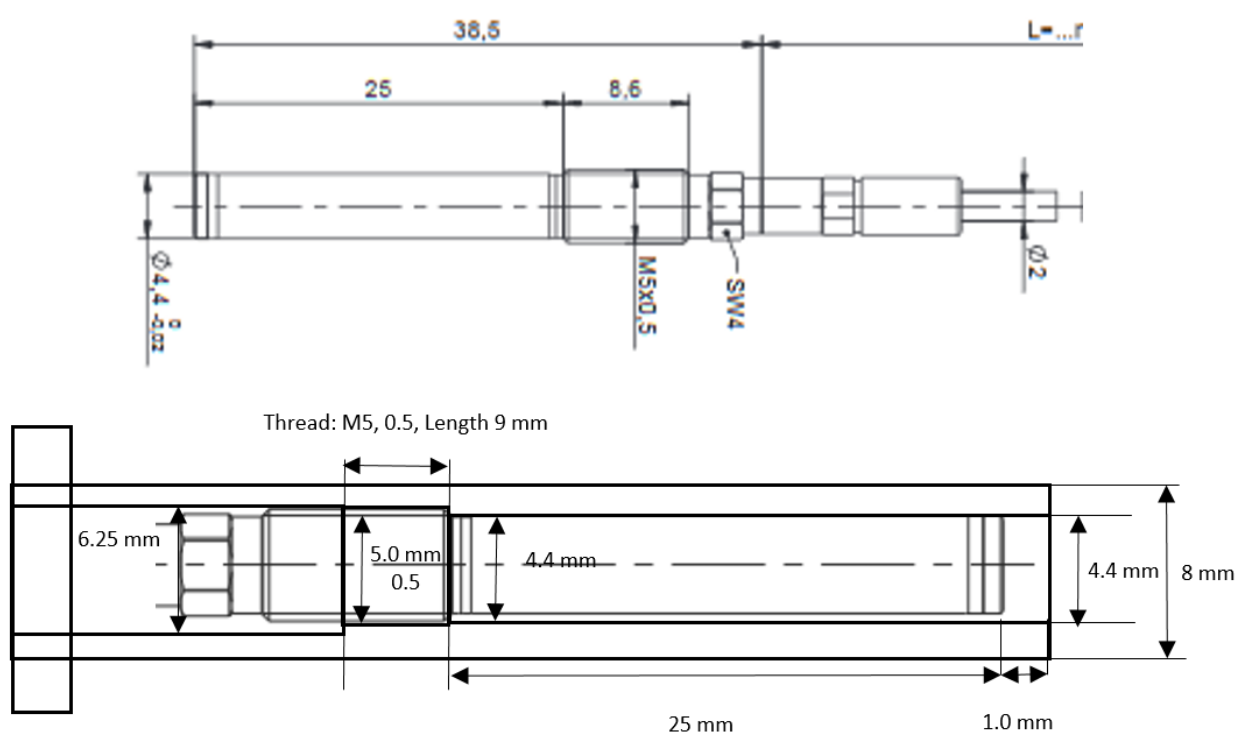

Figure 6-2: Pressure Transducer and Sleeve Modification

The transducer sleeve was screwed into the engine cylinder. A regular bolt is currently screwed onto the placement for the pressure transducer sleeve in the Figure 6-3 below. 


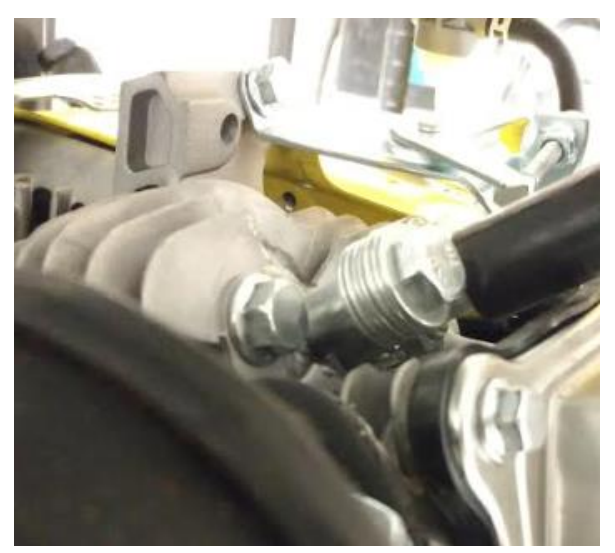

Figure 6-3: Pressure Transducer Sleeve Placement

The transducer sleeve ensured a stable pressure transducer and prevents the pressure transducer loosening throughout testing.

Due to the lack of a stable structure on the engine, the encoder was installed on metal brackets on the engine, which was then attached to the crankshaft using an extended metal thread as shown in Figure 6-4.

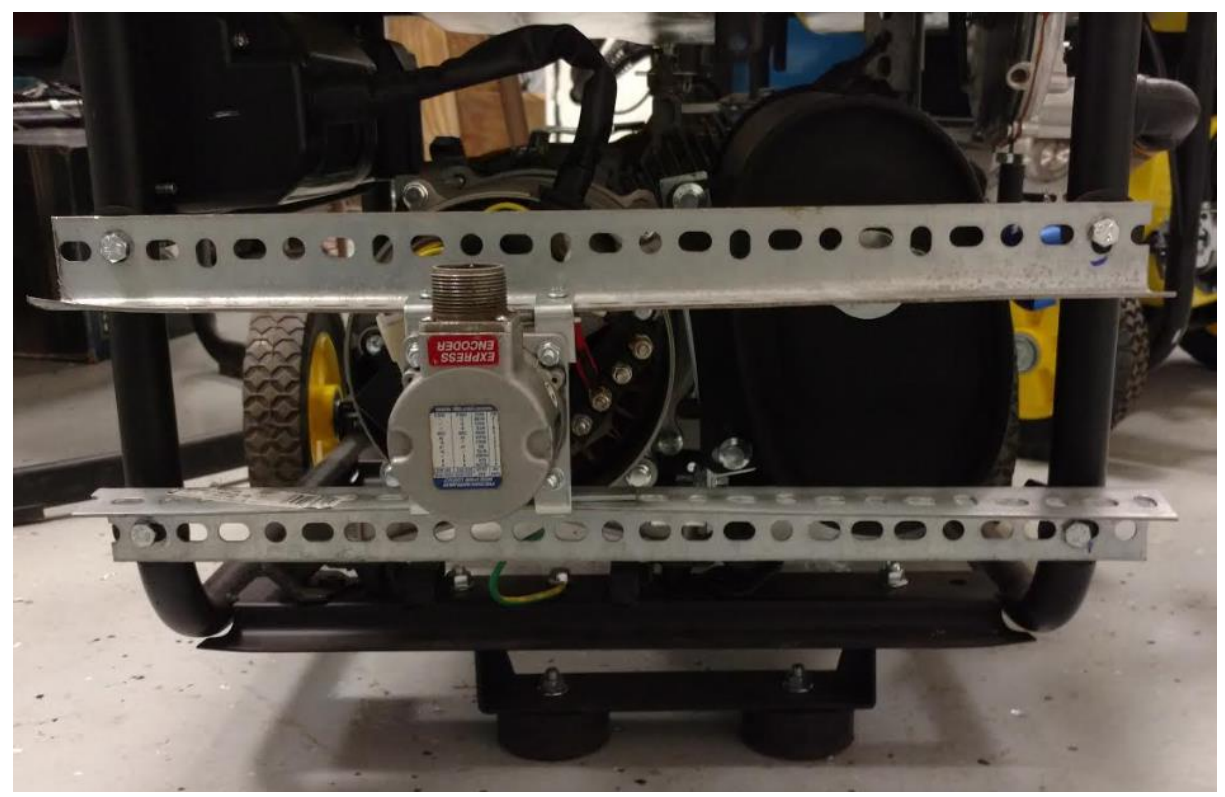

Figure 6-4: BEI H25 Incremental Encoder Mount Assembly 
The crank angle measuring device utilized was a BEI H25 incremental optical encoder, which was accurate to the nearest $0.5^{\circ} \mathrm{CA}$. The $\mathrm{NG}$ and liquid propane conversion kit from Century Fuel Products as shown in Figure 6-5 was installed onto the engine for $N G$ and liquid propane operation and testing. The process involved adding a metal adapter between the carburetor and air vent to attach the vapor hose to the regulator that was installed on the frame of the generator. Then a metal elbow was attached to a ball valve, which would be connected to the vapor hose installed with a high pressure regulator. The regulator would be attached to an adapter for connection directly with a gas tank.

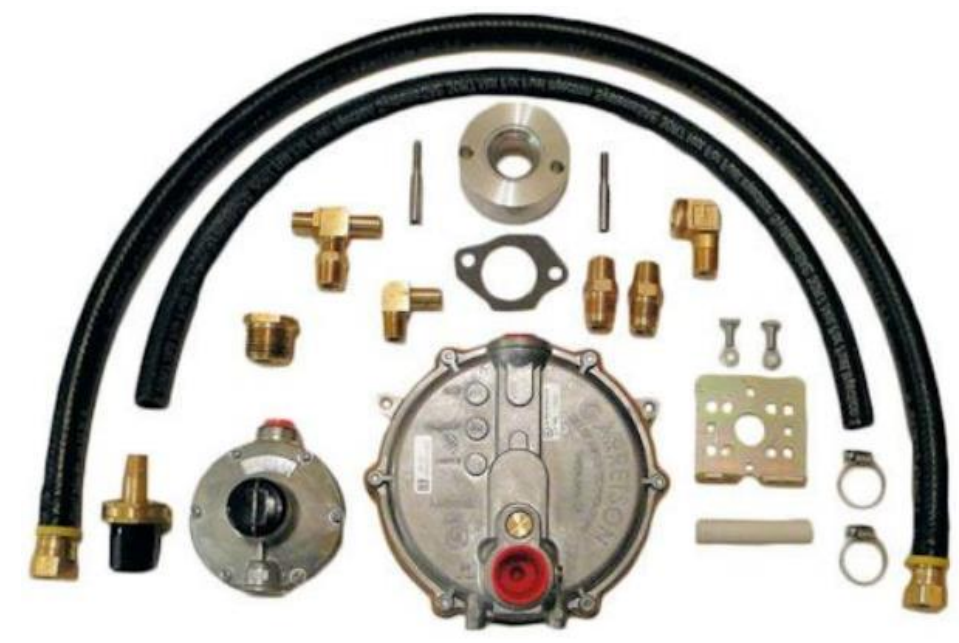

Figure 6-5: Century Link Tri-fuel Conversion Kit

However, since the sleeve that was required in the NG conversion kit blocked an airflow hole in the carburetor, the NG conversion kit would have to be removed during gasoline operation, which is currently the reason that the metal adapter is de-attached from the current engine set-up. This engine has been instrumented for fuel impact on combustion process and heat release rate research. 


\section{Chapter 7 Conclusion}

This research investigated the engine performance, combustion process, and exhaust emissions from a turbocharged SI WP-10 off-road engine developed to operate on gaseous fuels with a wide range of heating value (HHV range from 900 to $1400 \mathrm{BTU}$ ). A new method of calculating the specific heat ratio of the bulk gases was proposed and applied to calculate the heat release process. In addition, a scaling factor was proposed to increase the accuracy of the heat release calculations using Woschni equation. Based on the data presented in this research, the following conclusions can be drawn:

(1) The specific heat ratio calculated from temperature and bulk gas composition with the assumed complete combustion was lower than that derived from Log-P-Log $V$ diagram, especially during the combustion phase. Therefore, heat release rate calculated utilization method 1 may not accurately reflect the actual heat release rate.

(2) The scaling factor of engine operated on NG at full load was 0.34 . The scaling factor for fuel mixture of $\mathrm{NG}$ with $\mathrm{CO}_{2}$ and $\mathrm{NG}$ with propane was 0.33 , and 0.32 , respectively. The scaling factor of this SI gaseous fuel engine in the range of 0.32 to 0.34 was significantly higher than the default scaling factor of 0.12793 for SI gasoline engine determined by Woschni.

(3) Based on the results, the addition of $\mathrm{CO}_{2}$ will decrease the energy output with a $30 \%$ decrease in $\mathrm{CO}$ emissions and $5 \%$ decrease in $\mathrm{CO}_{2}$ emissions. Meanwhile the addition of propane will increase peak heat release and decrease combustion duration indicating the accelerated combustion process. 
(4) This SI gaseous fuel engine equipped with TWC is in compliance with EPA and CARB emissions regulations. Therefore, it can be interpreted that natural gas engines could continue to remain regulatory complaint with a functioning TWC.

\section{Future Work}

The research results presented in this research also suggests that the blending of propane to low BTU gases such as digester gas and landfill gas will provide technical solution for the seasonal variation in low BTU gases quality and quantity. This practice can also be considered as a new approach of burning propane at high thermal efficiency. In addition, blending an array of gaseous fuels may yield better economic results.

For further research, more variation of NG engines will have to be tested. In the past, there have been a large amount of research for heavy duty and medium duty engines. However, there has been few research reports on small and compact engines, such as the portable electric gas generator. In addition, different combinations of fuel mixtures will be required to be tested to determine if different combinations of the fuels would be able to offset the few disadvantages of NG. 


\section{Bibliography}

[1]United States, Congress, US Energy Information Administration. "Annual Energy Outlook 2018 with Projections to 2050." Annual Energy Outlook 2018 with Projections to 2050, US EIA, 2018, pp. 1-74.

[2] "Natural Gas Prices." Bp.com, British Petroleum, 2017,

www.bp.com/en/global/corporate/energy-economics/statistical-review-of-worldenergy/natural-gas/natural-gas-prices.html.

[3]"Short-Term Energy Outlook." U.S. Energy Information Administration - EIA Independent Statistics and Analysis, U.S. Energy Information Administration, July 2018, www.eia.gov/outlooks/steo/.

[4]Li, W., Liu, Z., Wang, Z., Li, C. et al., "Effect of $\mathrm{CO}_{2}, \mathrm{~N}_{2}$, and Ar on Combustion and Exhaust Emissions Performance in a Stoichiometric Natural Gas Engine," SAE Technical Paper 2014-01-2693, 2014, https://doi-

org.www.libproxy.wvu.edu/10.4271/2014-01-2693.

[5]Sezer, I. "Alternative Gaseous Fuels in Port Fuel Injection Spark Ignition Engines." Journal of the Energy Institute, 2011, doi:10.1179/174396711x13116932751958. [6]“Crude Oil Price Today | WTI OIL PRICE CHART | OIL PRICE PER BARREL | Markets Insider," Business Insider. http://markets.businessinsider.com/commodities/oilprice?type $=$ wti.

[7]"Natural Gas PRICE Today | Price of Natural Gas and Chart | Markets Insider," Business Insider. http://markets.businessinsider.com/commodities/natural-gas-price. [8]Hess, T. "U.S. Energy Information Administration - EIA - Independent Statistics and Analysis." EIA Expects Total U.S. Fossil Fuel Production to Reach Record Levels in 2018 and 2019 - Today in Energy - U.S. Energy Information Administration (EIA), U.S. Energy Information Administration, 18 Jan. 2018, www.eia.gov/todayinenergy/detail.php?id=34572.

[9] “Energy Use for Transportation.” US Energy Use in Transportation, U.S. Energy Information Administration (EIA), 23 May 2018, www.eia.gov/energyexplained/index.php?page=us_energy_transportation. 
[10]"Electricity in the United States." U.S. Energy Information Administration (EIA), 23 Apr. 2018,

https://www.eia.gov/energyexplained/index.php?page=electricity_in_the_united_states. [11]Ayandotun, B., Wasiu, A., Rashid, A. and Heikal, M., 2012. "The Effect of Carbon Dioxide Content-natural Gas on the Performance Characteristics of Engines: A Review." Journal of Applied Sciences, 12: 2346-2350.

[12]“World Energy Reserves." World Energy Council. 2013.

[13]EIA - Independent Statistics and Analysis. "How Much of the Oil Produced in the United States Is Consumed in the United States?" U.S. Energy Information Administration (EIA), U.S. Energy Information Administration, 27 Sept. 2017, www.eia.gov/tools/faqs/faq.php?id=268\&t=6.

[14]U.S. Energy Information Administration - EIA - Independent Statistics and Analysis. "U.S. Crude Oil and Natural Gas Proved Reserves," Year-End 2016, US Energy Information Administration, 2017, www.eia.gov/naturalgas/crudeoilreserves/. [15]U.S. Energy Information Administration - EIA - Independent Statistics and Analysis. "International Energy Statistics," US Energy Administration, 2018, www.eia.gov/beta/international/data/browser/.

[16]"Chemical Composition of Natural Gas." Union Gas, Enbridge Company, 2018, www.uniongas.com/about-us/about-natural-gas/Chemical-Composition-of-Natural-Gas. [17]Sevik, J., Pamminger, M., Wallner, T., Scarcelli, R. et al., "Performance, Efficiency and Emissions Assessment of Natural Gas Direct Injection compared to Gasoline and Natural Gas Port-Fuel Injection in an Automotive Engine," SAE Int. J. Engines 9(2):1130-1142, 2016, https://doi-org.www.libproxy.wvu.edu/10.4271/2016-01-0806. [18]Straub, D., et al. "Effects of Propane/Natural Gas Blended Fuels on Gas Turbine Pollutant Emissions." American Journal of Human Genetics; (United States), ASM International, Materials Park, OH, 1 Mar. 2007, www.osti.gov/servlets/purl/913263/. [19] Yang, C., Li, W., Yin, J., and Shen, Y., "Port Fuel Injection of CNG for Downsized 1Liter 3-Cylinder Turbocharged Engine with High Efficiency," SAE Technical Paper 201701-2275, 2017, doi:10.4271/2017-01-2275. 
[20] Sachdeva, A. and Mansuri, S., "Reduction of Pulsation Noise in CNG Vehicles," SAE Technical Paper 2013-26-0098, 2013, https://doiorg.www.libproxy.wvu.edu/10.4271/2013-26-0098.

[21]Anderson, J., Miers, S., Wallner, T., Stutenberg, K. et al., "Performance and Efficiency Assessment of a Production CNG Vehicle Compared to Its Gasoline Counterpart," SAE Technical Paper 2014-01-2694, 2014, doi:10.4271/2014-01-2694.

[22] Tate, I., "Opportunities for Alternative Solutions in the Off Highway Market", 9th Integer Emissions Summit \& DEF Forum, October 26 2016, Chicago.

[23] He, Z., Xu, Z., Zhu, L., Zhang, W. et al., "The Performances of a Spark Ignition Natural Gas Engine Coupled with In-Cylinder Thermochemical Fuel Reforming (TFR)," SAE Technical Paper 2016-01-2239, 2016, doi:10.4271/2016-01-2239.

[24] Adlercreutz, L., Cronhjort, A., Andersen, J., and Ogink, R., "Optimizing the Natural Gas Engine for $\mathrm{CO}_{2}$ reduction," SAE Technical Paper 2016-01-0875, 2016, doi:10.4271/2016-01-0875.

[25]Wu, W. and Ross, M., "Spark-Ignition Engine Fuel Consumption Modeling," SAE Technical Paper 1999-01-0554, 1999, https://doi-

org.www.libproxy.wvu.edu/10.4271/1999-01-0554.

[26]Kirwan, J., Shost, M., Roth, G., and Zizelman, J., "3-Cylinder Turbocharged

Gasoline Direct Injection: A High Value Solution for Low $\mathrm{CO}_{2}$ and NOx Emissions," SAE Int. J. Engines 3(1):355-371, 2010, https://doi-org.www.libproxy.wvu.edu/10.4271/201001-0590.

[27]Stanton, D., "Systematic Development of Highly Efficient and Clean Engines to Meet Future Commercial Vehicle Greenhouse Gas Regulations," SAE Int. J. Engines 6(3):1395-1480, 2013, https://doi-org.www.libproxy.wvu.edu/10.4271/2013-01-2421. [28] Abani, N., Nagar, N., Zermeno, R., chiang, M. et al., "Developing a 55\% BTE Commercial Heavy-Duty Opposed-Piston Engine without a Waste Heat Recovery System," SAE Technical Paper 2017-01-0638, 2017, https://doiorg.www.libproxy.wvu.edu/10.4271/2017-01-0638.

[29] Koeberlein, D., Supertruck Technologies for 55\% Thermal Efficiency and 68\% 
Freight Efficiency, Directions in Engine Efficiency, Detroit, MI. 2012.

[30] Thiruvengadam, S., Thiruvengadam, P., Besch, M., Carder, D., and Delgado, O. "Heavy - Duty Vehicle Diesel Engine Efficiency Evaluation and Energy Audit," The International Council on Clean Transportation Washington, DC, Oct. 2014. [31]APTA - "Transit on the Cutting Edge of Clean Technology". American Public Association Transportation. Policy Development and Research Report,2012 [32] ANGA - "Cleaner Transportation, Powered with Natural Gas". Available at: http://anga.us/blog/2013/5/16/cleanertransportation-powered-with-natural-gas. April 28 2014

[33] Escobar, K. "Driving to 54.5 MPG: The History of Fuel Economy." History of Fuel Economy: One Decade of Innovation, Two Decades of Inaction, April 202011 , www.pewtrusts.org/en/research-and-analysis/fact-sheets/2011/04/20/driving-to-545mpg-the-history-of-fuel-economy.

[34] The European Parliament and the Council of the European Union. "Regulation (EC) No 715/2007 of the European parliament and of the council of 20 June 2007 on type approval of motor vehicles with respect to emissions from light passenger and commercial vehicles (Euro 5 and Euro 6) and on access to vehicle repair and maintenance information." Official Journal 20 June 2007; OJL 171.

[35] Khalfan, A., Andrews, G., and Li, H., "Real World Driving: Emissions in Highly Congested Traffic," SAE Technical Paper 2017-01-2388, 2017, https://doiorg.www.libproxy.wvu.edu/10.4271/2017-01-2388.

[36] "Regulations for Greenhouse Gas Emissions from Passenger Cars and Trucks." EPA, Environmental Protection Agency, November 17 2016, www.epa.gov/regulationsemissions-vehicles-and-engines/regulations-greenhouse-gas-emissions-passengercars-and\#evaluation.

[37] Xi, Y., Ottinger, N., and Liu, Z., "The Dynamics of Methane and NO $\times$ Removal by a Three-Way Catalyst: A Transient Response Study," SAE Technical Paper 2018-011270, 2018, https://doi-org.www.libproxy.wvu.edu/10.4271/2018-01-1270. 
[38]Xi, Y., Ottinger, N., and Liu, Z., "Development of a Lab Reactor System for the Evaluation of Aftertreatment Catalysts for Stoichiometric Natural Gas Engines," SAE Technical Paper 2017-01-0999, 2017, https://doi-

org.www.libproxy.wvu.edu/10.4271/2017-01-0999.

[39] Gong, J., Wang, D., Brahma, A., Li, J. et al., "Lean Breakthrough Phenomena Analysis for TWC OBD on a Natural Gas Engine using a Dual-Site Dynamic Oxygen Storage Capacity Model," SAE Technical Paper 2017-01-0962, 2017, https://doiorg.www.libproxy.wvu.edu/10.4271/2017-01-0962.

[40]Nusselt, W., 1928. Der Warmeubergang zwischen Arbeitmedium und Zylinderwand in Kolbenmaschinen. Forachungsarb. Geb. Ing.

[41]Eichelberg, G. 1939. "Some New Investigations on Old Combustion Engine Problems." Engineering.

[42]Rozenblit, G. B. 1977. "Heat Transfer in Diesel Engines." Moscow, p. 30 - 170.

[43]Belinskiy, L. M. 1955. "Heat Transfer by Radiation in Combustion Chamber of High

- Speed Compression Ignited Engine." Moscow, Mashgiz, p. 100 - 300.

[44]Woschni, G., "A Universally Applicable Equation for Instantaneous Heat Transfer Coefficient in Internal Combustion Engine," SAE Paper 670931

[45]Hairruddin, A. A., et al. "Effect of Different Heat Transfer Models on a Diesel Homogeneous Charge Compression Ignition Engine." International Journal of Automotive and Mechanical Engineer, Dec. 2013.

[46]Przybyáa, G., et al. "The Heat Transfer Coefficient Calculation in the ICE Cylinder Based on In-Cylinder Pressure Data." Journal of KONES Powertrain and Transport, vol. 20, November 42013.

[47]Torregrosa, A., Olmeda, P., Romero, C. "Revings Engine Heat Transfer." Journal of Engineering annals of Faculty of Engineering Hunedoara, 2008.

[48] Heywood., B., J. 1989. Internal Combustion Engine Fundamentals. McGraw - Hill, New - York, p. 12 - 34, 143 - 197.

[49] Sanli, A., Sayin, C., Gumus, M., Kilicaslan, I., and Canakci., M. Numerical Evaluation by Models of Load and Spark Timing Effects on the In-Cylinder Heat 
Transfer of a SI Engine. Numerical Heat Transfer, Part A: Applications: An International Journal of Computation and Methodology, 56(5):444 - 458, 2009. [50] Sitkei, G. and Ramanaiah, G. V., "A Rational Approach for Calculation of Heat. Transfer in Diesel Engines," SAE Paper. 720027, 1972 


\section{Appendix}

Table A-1: Constant Values for Methane Shomate Equations

\begin{tabular}{|c|c|c|}
\hline \multicolumn{3}{|c|}{ Methane } \\
\hline Temperature (K) & $298 .-1300$. & $1300 .-6000$. \\
\hline A & -0.703029 & 85.81217 \\
\hline B & 108.4773 & 11.26467 \\
\hline C & -42.52157 & -2.114146 \\
\hline D & 5.862788 & 0.13819 \\
\hline E & 0.678565 & -26.42221 \\
\hline F & -76.84376 & -153.5327 \\
\hline G & 158.7163 & 224.4143 \\
\hline H & -74.8731 & -74.8731 \\
\hline
\end{tabular}

Table A-2:Constant Value for Oxygen Shomate Equations

\begin{tabular}{|c|c|c|c|}
\hline \multicolumn{5}{|c|}{ Oxygen } \\
\hline Temperature (K) & $100 .-700$. & $700 .-2000$. & $2000 .-6000$. \\
\hline A & 31.32234 & 30.03235 & 20.91111 \\
\hline B & -20.23531 & 8.772972 & 10.72071 \\
\hline C & 57.86644 & -3.988133 & -2.020498 \\
\hline D & -36.50624 & 0.788313 & 0.146449 \\
\hline E & -0.007374 & -0.741599 & 9.245722 \\
\hline F & -8.903471 & -11.32468 & 5.337651 \\
\hline G & 246.7945 & 236.1663 & 237.6185 \\
\hline H & 0 & 0 & 0 \\
\hline
\end{tabular}

Table A-3: Constant Value for Nitrogen Shomate Equations

\begin{tabular}{|c|c|c|c|}
\hline \multicolumn{5}{|c|}{ Nitrogen } \\
\hline Temperature (K) & $100 .-500$. & $500 .-2000$. & $2000 .-6000$. \\
\hline A & 28.98641 & 19.50583 & 35.51872 \\
\hline B & 1.853978 & 19.88705 & 1.128728 \\
\hline C & -9.647459 & -8.598535 & -0.196103 \\
\hline D & 16.63537 & 1.369784 & 0.014662 \\
\hline E & 0.000117 & 0.527601 & -4.55376 \\
\hline F & -8.671914 & -4.935202 & -18.97091 \\
\hline G & 226.4168 & 212.39 & 224.981 \\
\hline H & 0 & 0 & 0 \\
\hline
\end{tabular}


Table A-4: Constant Value for Carbon Dioxide Shomate Equations

\begin{tabular}{|c|c|c|}
\hline \multicolumn{3}{|c|}{ Carbon Dioxide } \\
\hline $\begin{array}{c}\text { Temperature } \\
\text { (K) }\end{array}$ & $\begin{array}{c}298 .- \\
1200 .\end{array}$ & $\begin{array}{c}1200 .- \\
6000 .\end{array}$ \\
\hline A & 24.99735 & 58.16639 \\
\hline B & 55.18696 & 2.720074 \\
\hline C & -33.69137 & -0.492289 \\
\hline D & 7.948387 & 0.038844 \\
\hline E & -0.136638 & -6.447293 \\
\hline F & -403.6075 & -425.9186 \\
\hline G & 228.2431 & 263.6125 \\
\hline H & -393.5224 & -393.5224 \\
\hline
\end{tabular}

Table A-5: Constant Value for Water(Gas) Shomate Equations

\begin{tabular}{|c|c|c|}
\hline \multicolumn{3}{|c|}{ Water (Gas) } \\
\hline $\begin{array}{c}\text { Temperature } \\
\text { (K) }\end{array}$ & $500 .-$ & $1700 .-$ \\
A & 1700. & 6000. \\
\hline B & 6.832514 & 41.96426 \\
\hline C & 6.793435 & -1.4922053 \\
\hline D & -2.53448 & 0.098119 \\
\hline E & 0.082139 & -11.15764 \\
\hline F & -250.881 & -272.1797 \\
\hline G & 223.3967 & 219.7809 \\
\hline H & -241.8264 & -241.8264 \\
\hline
\end{tabular}

